\title{
Information about price and volatility jumps inferred from options prices
}

\author{
Stephen J. Taylor ${ }^{1} \quad$ Chi-Feng Tzeng ${ }^{2} \quad$ Martin Widdicks $^{3}$
}

4 February 2018

\section{Accepted for publication in the Journal of Futures Markets}

\begin{abstract}
High-frequency jump tests are applied to the prices of both futures contracts and their options, to infer the properties of jumps in the price and volatility of the underlying asset. Empirical results for FTSE 100 contracts detect frequent jumps in futures, call and put prices. Jumps in futures prices are more important than any jumps in volatility when the market determines option prices. The empirical evidence is consistent with futures prices following affine jumpdiffusion processes, containing either futures price jumps or contemporaneous futures price and volatility jumps, providing jump risk premia are included in the price dynamics.

\footnotetext{
${ }^{1}$ Department of Accounting and Finance, Lancaster University Management School, UK.

${ }^{2}$ Department of Quantitative Finance, National Tsing Hua University, Taiwan

${ }^{3}$ Department of Finance, University of Illinois at Urbana-Champaign, USA
}

\section{ACKNOWLEDGMENTS}

For their advice and comments, the authors thank the editor, the referee and participants at the 2014 conference on high frequency data and derivative markets held in Auckland, the 2016 EFMA annual meeting in Basel and the 2017 international conference on futures and other derivatives held at Ningbo, as well as a seminar audience at National Taiwan University. They particularly Ihsan Badshah, Stephen Figlewski, Jianhua Gang, Xin Huang and Matthias Peter. Chi-Feng Tzeng thanks the Ministry of Science and Technology and National Tsing Hua University for providing financial support. 


\section{INTRODUCTION}

Over recent decades, stock market jumps have posed a great challenge to financial research and options pricing models. Two types of empirical evidence have clearly shown that stock market prices jump. Firstly, studies of daily (i.e. low-frequency) prices using stochastic volatility models have found strong evidence of jumps in both price and volatility (Chernov, Gallant, Ghysels, \& Tauchen, 2003; Eraker, Johannes, \& Polson, 2003). Secondly, nonparametric studies of intraday (i.e. high-frequency) prices find conclusive evidence that there are jumps during intervals of a few minutes for stocks and stock index futures (Andersen, Bollerslev, \& Dobrev, 2007; Bollerslev, Law, \& Tauchen, 2008).

We innovate by expanding the high-frequency, jump literature to include tests for jumps in option prices and thereby provide original evidence concerning jumps in volatility. ${ }^{1}$ We also explore how necessary jump risk premia are when explaining the frequencies of observed jumps in futures prices and options prices.

Duffie, Pan, and Singleton (2000) showed how to price options for a general affine jumpdiffusion (AJD) process. They illustrated the result that simultaneous jumps in price and volatility can describe the smirk observed in implied volatilities. Jump risk premia are important for AJD valuation of options, because price and volatility jumps cannot be hedged like diffusive risks. Pan (2002) used the generalized method of moments to estimate AJD parameters and a price jump risk premium. Broadie, Chernov, and Johannes (2007) showed that consideration of several risk premia associated with jumps may improve AJD option pricing models. High-frequency research has shown that there exist cojumps across stocks for which risk is non-diversifiable (Bollerslev, Law, \& Tauchen, 2008).

Carr and $\mathrm{Wu}(2009)$ used the difference between the realised variance and the variance swap rate to determine the variance risk premium. They found a negative variance risk premium for U.S. equities, indicating that investors were averse to an increase in volatility, and were willing to pay a premium to hedge against it. Furthermore, Bollerslev and Todorov (2011) proposed new extreme value methods to estimate the jump tails for real-world and risk-neutral measures. Their findings suggested that a substantial part of the historical equity and variance 
risk premia may be explained by compensation for tail risk associated with large, negative, price jumps. Also see Todorov (2010) for more analysis of the interaction between jumps and the variance risk premium.

Thus far, affine models with compound Poisson jumps have been widely used for describing the return and volatility processes in financial markets. Todorov and Tauchen (2011) concluded that a jump diffusion was a suitable process for high-frequency, S\&P 500 index levels, whereas the VIX index required a pure-jump process to capture frequent jumps. An alternative methodology, which we follow, is to use options prices directly to investigate price jumps, volatility jumps and the associated risk premia.

We use a high-frequency jump test, outlined in Section 2, to detect jumps in futures and options prices. The main idea is that, when there is no contemporaneous volatility jump, a jump in the (underlying asset) price induces jumps in call prices in the same direction as the underlying asset price and jumps in put prices in the opposite direction. In contrast, a jump in volatility induces jumps in call prices and jumps in put prices in the same direction, when there is no contemporaneous price jump. Therefore, if there are contemporaneous call jumps and put jumps in the same direction then we regard this as evidence in favour of jumps in volatility. We argue that the Andersen, Bollerslev, and Dobrev (2007) jump test is equally applicable to futures and options prices. Monte Carlo evidence, presented in Section 3, confirms that the test provides reliable evidence for AJD processes.

The empirical results presented in Section 4 are for FTSE contracts, from January 2005 to December 2009. We confirm prior results that jumps exist in futures prices and also detect more jumps in option prices than in futures prices. However, we fail to find strong evidence for jumps in volatility. Jumps in the same direction are observed for less than $2 \%$ of the occasions when jumps are detected in both the call price and the put price. In addition, it is possible that the rare large price changes in the same direction may have resulted from microstructure effects or other types of noise in the price data.

The negative result about the directions of the call and put jumps leads to two possible explanations. It may be that some jumps in futures prices occur contemporaneously with jumps in volatility, and that jumps in futures prices have a greater impact on option prices than the 
matching volatility jumps. Alternatively, there are simply no jumps in volatility. To compare the plausibility of these explanations, further simulations of the jump test applied to AJD processes are evaluated in Section 5 for three scenarios: only price jumps; independent price jumps and volatility jumps; and contemporaneous price jumps and volatility jumps. From a comparison between the empirical and simulation results, we find there are price jumps and priced jump risk premia, and that any jumps in volatility occur when the futures price jumps. The critical jump risk premia appear to be the differences between the real-world and riskneutral moments of the futures price jumps and not necessarily those of the volatility jumps[WM1].

\section{DETECTING JUMPS}

\subsection{Price variation}

We assume in our theoretical analysis that the price of an asset follows a semi-martingale process in continuous time, so microstructure noise is ignored. The logarithm of the asset price, denoted $p_{t}$, then follows a standard jump-diffusion process, which can be represented by the stochastic differential equation

$$
d p=\mu d t+\sigma d W+J d N
$$

where the drift rate $\mu_{t}$ has locally bounded variation, the volatility process $\sigma_{t}$ is positive, $W_{t}$ is a standard Wiener process, $N_{t}$ counts price jumps and $J_{t}$ represents the size of any jump at timet. The return during an interval of $\Delta$ time units, from time $t-\Delta$ until time $t$ equals $p_{t}-p_{t-\Delta}$

We let one time unit equal the duration of trading at a market for one day, from the open until the close, and divide it into $m$ time steps. We define a set of $m$ intraday returns for day $d$ by $r_{d, j}=p_{d+j / m}-p_{d+(j-1) / m}$. The realized variance and the realized bipower variation for day $d$ are respectively defined by

$$
R V_{d}=\sum_{j=1}^{m} r_{d, j}^{2}
$$

and

$$
B V_{d}=\frac{\pi m}{2(m-1)} \sum_{j=2}^{m}\left|r_{d, j}\right|\left|r_{d, j-1}\right|
$$


Andersen and Bollerslev (1998), Comte and Renault (1998), and Barndorff-Nielsen and Shephard $(2001,2004)$ showed that these quantities converge as $m \rightarrow \infty$. The realized bipower variation converges to the integrated variance,

$$
B V_{d} \rightarrow \int_{d}^{d+1} \sigma_{s}^{2} d s
$$

while the realized variance converges to the quadratic variation, which equals the integrated variance plus the sum of the squared jumps:

$$
R V_{d} \rightarrow \int_{d}^{d+1} \sigma_{s}^{2} d s+\sum_{d<s \leq d+1} J_{s}^{2}
$$

\subsection{Detecting index jumps}

Intuitively, a return contains a jump if the return is large compared with the variation expected when the price follows a diffusion process. A simple implementation of the test methodology developed by Andersen, Bollerslev, and Dobrev (2007) identifies an index return as containing a jump whenever

$$
\left|r_{d, j}\right|>z_{m} \sqrt{B V_{d} / m}
$$

with $Z_{m}$ determined by the significance level of the hypothesis test and the standard normal distribution. The test criterion in (6) assumes it is appropriate to estimate the integrated variance of an intraday return as the daily variation divided by $m$, i.e. it is assumed that intraday volatility changes are not important. ABD ensure their evidence for jumps is conclusive by selecting a very low significance level. Let $\alpha$ be the daily Type I error rate, which is the proportion of days without jumps for which the test procedure claims one or more jumps. Then each of the $m$ intraday returns should be tested with a significance level $\alpha_{m}$ satisfying $\left(1-\alpha_{m}\right)^{m}=1-\alpha$. ABD choose $\alpha=10^{-5}$ and test 195 two-minute returns each day, and then $z_{m}=5.45$.

As there are well-documented intraday patterns in volatility, it is natural to modify (6) to identify a jump within a return whenever

$$
\left|r_{d, j}\right|>z_{m} \sqrt{f_{j} B V_{d}}
$$

with $f_{j}$ an estimate of the proportion of the day's variance which occurs during intraday period $j$. The ABD test will detect jumps which are sufficiently large. The test will, however, fail to 
detect relatively small jumps and thus it may detect only a small fraction of the jumps in a price process (Taylor, 2010).

\subsection{Detecting jumps in options prices}

The price of an option follows a semi-martingale process whenever the price of the underlying asset has the semi-martingale property. Consequently, it is tempting to detect jumps in options prices using the methods which have already been successfully applied to index levels.

A simple example shows, however, that extra care may be required if the ABD test is applied to options prices. When the underlying asset price $S$ follows a geometric Brownian process,

$$
\frac{d s}{S}=\mu d t+\sigma d W
$$

by Ito's lemma the call price $C$ follows the diffusion process

$$
\frac{d C}{C}=\frac{1}{C}\left(\frac{\partial C}{\partial t}+\frac{\partial C}{\partial S} \mu S+\frac{1}{2} \sigma^{2} S^{2} \frac{\partial^{2} C}{\partial S^{2}}\right) d t+\sigma \frac{S}{C} \frac{\partial C}{\partial S} d W .
$$

There will then be intraday variation in the volatility of call returns, because of the multiplicative term $(S / C)(\partial C / \partial S)$. We therefore expect that there will always be more intraday volatility variation for changes in options prices than for changes in the underlying asset prices. To verify this we use Monte Carlo simulations in Section 3 to determine if the ABD methodology remains viable when it is applied to options prices.[WM2]

\subsection{Detecting jumps in volatility}

The general jump-diffusion specification given by (1) permits jumps in both prices and the volatility component $\sigma_{t}$. Our empirical results are for an underlying asset which is a futures contract on a stock index. Assuming efficient markets, a jump in the futures price (without a contemporaneous volatility jump) will induce all call prices to jump in the same direction as the futures price and all put prices to jump in the opposite direction. In contrast, a jump in the volatility (without a contemporaneous futures price jump) will induce all call and all put prices 
to jump in the same direction. Although theoretical predictions are less precise when both the futures price and the volatility jump at the same time, call and put prices will only move in the same direction when the volatility jump is large relative to the jump in the futures price.

Whenever the ABD test detects contemporaneous jumps in call and put prices in the same direction we will regard this as evidence in favour of a volatility jump. Such evidence may be elusive, however, because contemporaneous jumps in the futures price may hide the impact of volatility jumps.

\section{MONTE CARLO RESULTS}

We first use Monte Carlo methods to assess the size and power of the ABD test applied to asset and option prices for a selection of stochastic processes. The processes are defined in Sections 3.1 and 3.2, and the results are discussed in Sections 3.3.

Size is defined as the proportion of simulated periods containing no price jumps for which the test falsely claims a price jump has occurred. Power is the proportion containing a price jump for which the test correctly asserts a jump has occurred. A jump in volatility (denoted J.V.) and/or a jump in the underlying asset price (denoted J.P.) should cause a jump in all option prices. The intraday size, $\alpha_{m}$, and power, $1-\beta$, of the ABD test for asset prices and option prices are listed as follows:

\begin{tabular}{c|cc} 
& (underlying asset) Prices & Options \\
\hline$\alpha_{m}$ & $\frac{\text { number of detected J.P. } \neq 0 \mid \text { true J.P. }=}{\text { number of true J.P. }=0}$ & $\frac{\text { number of detected J.Options } \neq 0 \mid \text { true J.P. }=0 \& J . V .=0}{\text { number of true J.P. }=0 \& J . V .=0}$ \\
$1-\beta$ & $\frac{\text { number of detected J.P. } \neq 0 \mid \text { true J.P. } \neq}{\text { number of true J.P. } \neq 0}$ & $\frac{\text { number of detected J.Options } \neq 0 \mid \text { true J.P. } \neq 0 \& / o r \quad J . V . \neq}{\text { number of true J.P. } \neq 0 \text { \&/or J.V. } \neq 0}$
\end{tabular}

When $m$ prices a day are simulated, the estimated intraday size $\hat{\alpha}_{m}$ is converted to the equivalent daily figure $\hat{\alpha}$ given by $\left(1-\hat{\alpha}_{m}\right)^{m}=1-\hat{\alpha}$. 


\subsection{Affine stochastic processes}

The general form of the simulated affine stochastic processes for the logarithms of prices is as follows:

$$
\begin{gathered}
d p=(r+\gamma-0.5 V) d t+\sqrt{V} d W+J^{p} d N^{p}-\lambda^{p} \bar{\mu}^{p} d t \\
d V=\kappa(\theta-V) d t+\xi \sqrt{V} d Z+J^{V} d N^{V}
\end{gathered}
$$

with correlation $\rho$ between the Wiener processes $W_{t}$ and $Z_{t}$. The two jump processes, $N_{t}^{p}$ and $N_{t}^{\mathrm{V}}$, are Poisson processes which are independent of the Wiener processes. The four constants in (10) are the risk-free rate $r$, the equity risk premium $\gamma$, the price jump intensity $\lambda^{p}$ and the drift compensator $\bar{\mu}^{p}=E\left[\exp \left(J_{t}^{p}\right)-1\right]$ for which $\left(\sum_{s \leq t} \exp \left(J_{s}^{p}\right)-1\right)-\lambda^{p} \bar{\mu}^{p} t$ is a martingale process.

We consider five special cases of the general specification above:

1. Geometric Brownian motion, when $V_{t}$ is constant and the jump components are removed.

2. The stochastic volatility model of Heston (1993), defined by removing both jump components. The variance $V_{t}$ of this SV model mean-reverts towards the level $\theta$ at a rate determined by $\kappa$. This and the following cases are all special cases of a general affine specification in Duffie, Pan, and Singleton (2000).

3. The SVJP model which includes jumps in prices alone, as in Bates (1996). The jumps are normally distributed, with mean $\mu$ and variance $\sigma^{2}$.

4. The SVIJ model containing stochastically independent jump processes. The price jumps are again normal with mean $\mu$ and variance $\sigma^{2}$. The jumps in volatility have intensity $\lambda^{V}$ and their sizes are exponentially distributed with mean $\mu^{V}$.

5. The SVCJ model having contemporaneous jumps in price and volatility, so $N_{t}^{p}=N_{t}^{V}$. The volatility jump properties remain as for Case 4 , but the conditional means of the price jumps are now a linear function of the volatility jumps; the conditional distributions are defined by $J_{t}^{p} \mid J_{t}^{V} \sim N\left(\mu+\beta J_{t}^{V}, \sigma^{2}\right)$.

The drift compensator is $\bar{\mu}^{p}=\exp \left(\mu+0.5 \sigma^{2}\right)-1$ for Cases 3 and 4 , and it equals $\bar{\mu}^{p}=\left(\exp \left(\mu+0.5 \sigma^{2}\right)-1\right) /\left(1-\beta \mu^{V}\right)$ for Case 5 . 


\subsection{Risk-neutral affine processes}

The simulated prices of options are obtained by assuming the risk-neutral dynamics of the underlying asset have the same affine structure as the real-world processes defined above. Following Broadie, Chernov, and Johannes (2007) and Branger, Hansis, and Schlag (2010), five risk premia terms are created by changing the real-world parameters $\mu, \sigma, \mu^{V}, \kappa, \lambda^{p}$ to risk-neutral parameters $\tilde{\mu}, \tilde{\sigma}, \tilde{\mu}^{V}, \tilde{\kappa}, \tilde{\lambda}^{p}$. The differences $\mu-\tilde{\mu}, \tilde{\sigma}-\sigma, \tilde{\mu}^{V}-\mu^{V}, \tilde{\kappa}-\kappa, \tilde{\lambda}^{p}-$ $\lambda^{p}$, are respectively labelled the risk premia for the mean price jump, the volatility of price jumps, the mean volatility jump, the diffusive volatility and the jump intensity ${ }^{2}$. The first two differences are together referred to as price jump risk premia. We suppose $\lambda^{p}$ equals $\lambda^{V}$ for the SVIJ model, and likewise for the risk-neutral process. All the remaining parameters, namely $\theta, \xi, \rho$ and $\beta$, are identical for the real-world and risk-neutral specifications.

Exact options prices can be obtained by inverting characteristic functions. We use the Duffie, Pan, and Singleton (2000) pricing formula to calculate all options prices.

\subsection{Results}

This section determines when it is reasonable to apply the ABD jump detection test on index and options prices for affine stochastic processes. We find that the true size of the test is often higher than the nominal significance level, hence small significance levels are essential for empirical tests. We also find that the test is capable of finding some jumps when they are present, but only finds a small proportion when jumps occur frequently.

In all of the simulations, we set $m=144$; for a trading day of 504 minutes, this value corresponds to the calculation of returns once every 3.5 minutes.

\subsubsection{Constant volatility, no jumps}

The simulated sizes for the jump test obtained from a simulation of geometric Brownian motion for 200,000 days are listed in Table 1 . When the annual volatility $\sigma$ is set to $10 \%, 14 \%$, and 
$22 \%$, representing levels for low, average and high volatility respectively, the daily sizes of the test applied to options returns are approximately $1.6 \%, 0.2 \%, 0.03 \%$ and $0.006 \%$ at the $1 \%$, $0.1 \%, 0.01 \%$ and $0.001 \%$ nominal significance levels, respectively. The sizes of the ABD test applied to futures returns are lower, but slightly larger than the nominal levels. This is consistent with the estimates presented by Andersen, Bollerslev, and Dobrev (2007). The size of the call option test does not increase when the diffusion coefficient of the call return increases and the call prices become more volatile. Specifically, the size does not increase for more volatile, out-of-the-money options prices. The nominal values of the ABD test are approximately valid and very few jumps will be falsely identified when the significance level is $0.1 \%$ or less.

\subsubsection{Stochastic volatility models}

We next discuss simulation results for jump tests applied to affine jump-diffusion models. The parameters settings are shown in Panel A of Table 6, which are estimates obtained from our FTSE prices using methods described in Section 5. Panel A of Table 2 presents the sizes of the jump test for the SV model for futures, and for options across three moneyness levels. All the sizes are slightly greater than those for constant volatility (Table 1) and the maximum value is $0.25 \%$ when the significance level is $0.1 \%$.

Panel B of Table 2 shows our first results when there are jumps in prices. We select a high annual jump intensity, namely $\lambda=2,300$ (about 10 on an average trading day). This ensures the rate of detected jumps in futures prices is similar for the SVJP model, at one every fourteen days, to the rate detected for two-minute returns from S\&P 500 futures by Andersen, Bollerslev, and Dobrev (2007) with a daily significance level of $0.001 \%$ level; the power of the test is then approximately $0.8 \%$. The sizes for the SVJP model are often less than the set significance levels. The powers of the index tests and the options tests are low, implying that only a small fraction of the jumps are identified. As jumps occur contemporaneously in all prices for the SVJP model, the number of correctly identified jumps in the index is of a similar magnitude to the number of detected jumps in the options. All power estimates in Panel B are between $4.32 \%$ and $6.98 \%$ when the daily significance level is $1 \%$. It is, however, seen that more option jumps are detected than futures jumps for reasons we discussed in Section 2.3. 
Next we consider jumps in both prices and volatility. Panel $\mathrm{C}$ of Table 2 shows results when the two types of jump occur independently (the SVIJ model). The estimated test sizes are similar to the SVJP values, while test power is now reduced for option prices but not for the futures prices. A comparison of Panel A of Table 3, for contemporaneous price and volatility jumps (the SVCJ model), with Panel C of Table 2 shows that the ABD jump test has similar size and more power for the SVCJ model compared with the results for the SVIJ model. The contemporaneous jumps magnify spikes in futures returns, and increase the magnitudes of options returns. Consequently, the ABD test can detect contemporaneous jumps. From Table 3 , it is again seen that more option jumps are detected than futures jumps. It is also noted that the test size for the SVCJ model is inaccurate when volatility is low, option prices are out-ofthe-money and the significance level is very low.

\section{EMPIRICAL RESULTS}

\subsection{Data and sampling frequency}

The data consists of FTSE 100 high-frequency futures and option prices, collected from Euronext. The maturity date of the futures contracts is the third Friday of each quarter, while the options expire on the third Friday of each month. The sample period is from January 4 , 2005 to December 31, 2009, a total of 1,262 trading days. During this period, futures were traded from 8:00 to 17:30 and options from 8:00 to 16:30. For reasons given later, we study prices from 8:06 to 16:30 inclusive. All times are for London, which is usually five hours ahead of New York.

The prices studied are midquotes defined as the averages of the most competitive bid and ask prices. Quotation times are recorded to an accuracy of one second. There are fixed times during the day when prices are required (e.g. 8:06:00 and 8:09:30) and we use the latest prices recorded at or before these times.

Three time series of options prices are studied:

1) Matm: At-the-money options with a monthly cycle of expiration dates, 
2) Motm: Out-of-the-money options with a monthly cycle of expiration dates,

3) Qatm- At-the-money options with a quarterly cycle of expiration dates.

At-the-money is defined by a daily fixed strike price which is the closest to the midpoint of the day's range for the underlying futures prices. The out-of-the-money call (put) strike price is selected to be the at-the-money strike price plus (minus) $50 .^{3}$ The option and futures expiry dates are the nearest to expiry for which the remaining time is at least five trading days.

The days with missing data are deleted, defined as those days for which there is at least one twenty-minute period which has no recorded prices. A few days containing either large price spikes at the open or close of trading or serious violations of put-call parity ${ }^{4}$ are also deleted. For example, the call prices are highly volatile within one hour around the London terrorist incident on July 7, 2005. For each series of options prices, there are 808 daily samples available. The sample period is divided into the low volatility period from January 2005 to June 2007 and the high volatility period from July 2007 to December 2009. There are 369 and 439 sample days in the low and high volatility periods, respectively.

To choose the sample period and the data frequency, we take into account the following principles:

1. To obtain more information, we extract the data from as wide a period of trading time as possible.

2. The futures and options prices are studied for the same period of time.

3. For options data, we avoid time intervals which end when major U.S. macroeconomic announcements are made, specifically at 13:30 and 15:00. Doing so reduces noise and realized variance, and thus we can more accurately detect jumps.

After considering the above principles, we extract price data during the intraday period between 8:06 and 16:30 inclusive, a total of 504 minutes. To illustrate why we avoid price records at 13:30 and 15:00, Figure 1A presents the monthly out-of-the-money options prices at the 15-second frequency on January 13, 2006. It is obvious that the spikes in put prices at 13:30 and 15:00 violate put-call parity. Figure 1D restricts the options prices to the 5-minute frequency from 8:10 to $16: 30$ and shows that the spikes are then selected. In contrast, Figure $1 \mathrm{C}$ presents the options prices at the 3.5-minute frequency, starting at 8:06; none of the time intervals then ends at exactly 13:30 or 15:00 and there are no spikes shown. By using a 3.5- 
minute frequency, instead of the popular 5-minute frequency, we can reduce the number of unsatisfactory days containing unusual price spikes within the selected data from 54 to 15 out of the 808 sample days.

Figure 2 contains four signature plots ${ }^{5}$, which illustrate the relationship between frequency and the mean realized variance ${ }^{6}$, when the first price each day is at 8:06. The selected times for the first three frequencies (namely 15 seconds, 30 seconds and 1 minute) include 13:30 and 15:00, while the times for the lower frequencies do not include these specific times. The mean realized variances across various frequencies are used to seek the best trade-off point which ideally maximises the benefit from obtaining additional information through more frequent sampling while avoiding measurement errors from microstructure noise and bid-ask bounce effects. It is seen from Figure 2 that, as the time between price measurements decreases, the mean realized variances of calls and puts decrease slightly and reach a stable value generally at the 3.5-minute frequency. The mean realized variances of OTM calls and puts with 3.5minute frequency during the periods commencing at 8:06 are 0.0964 and 0.0797. These averages are less than their counterparties during the periods starting at 8:10; Figure 3A shows averages of 0.1174 and 0.0872 for OTM calls and puts with a 2-minute frequency, similar to 0.1118 and 0.0868 for the 5-minute frequency. These observations support the claim that choosing the 3.5-minute frequency is an optimal choice for our options data. Figure 2D shows the futures mean realized variances are similar across frequencies and thus selecting the 3.5minute frequency is also appropriate for the futures data.

The variance proportion $f_{j}$ is the average proportion of realized variance associated with intraday period $j$. Figure 4 shows and defines estimated proportions for the 3.5-minute frequency, for futures, call and put prices. The timings of spikes in these proportions are similar across futures and options. There are spikes at the beginning and end of the trading period. There are also high values around 12:30, 13:30, 14:00 and 15:00 reflecting US macro news. The variance proportions are generally higher after the US markets open at 14:30. These results are consistent with the findings of Areal and Taylor (2002) for FTSE 100 futures returns.

\subsection{Detected jumps}


To ensure that the evidence for the existence of jumps is convincing, we chose four low daily significance levels $(\alpha)$, decreasing from $1 \%$ to $0.001 \%$. Panel A of Table 4 shows the numbers of detected jumps in the futures prices and the OTM options prices, with monthly expirations. The counts of detected jumps in the futures prices approximately double when the significance level is multiplied by 10. Section 5.2.2 shows that this doubling effect occurs when futures prices are simulated with stochastic volatility and jumps in price. For the $0.1 \%$ level, we expect 0.8 detected jumps across the entire dataset when the true test size equals the significance level and the price process is continuous. This expectation is at most 2 detected jumps from the Monte Carlo results in Tables 1, 2 and 3. As we observe 150 detected futures jumps at the $0.1 \%$ level, this is indeed compelling evidence for jumps in the futures prices; the rate of detected jumps is then approximately one a week and $46 \%$ of these detected jumps are positive.

Moreover, the number of detected jumps in options prices is greater than that in futures prices, which is consistent with the Monte Carlo evidence in Tables 2 and 3 . At the $0.1 \%$ level, there are 217 detected jumps in call prices and 228 in put prices which is very strong evidence for jumps in options prices; $47 \%$ of the call jumps and $51 \%$ of the put jumps are positive. The counts approximately halve when the significance level is divided by ten and the call counts are near the put counts, except for the tiny level of $0.001 \%$ when there are notably more put jumps than call jumps.

We next consider the types of price jumps occurring concurrently. We allocate the jumps to eight combinations, which list which jumps are detected during the same 3.5-minute period. Panel A of Table 4 shows that the most common combination at the $1 \%, 0.1 \%$ and $0.01 \%$ levels is FCP, which represents contemporaneous detected jumps in futures, call and put prices, and it then accounts for about $26 \%$ of the combinations. Combination $\mathrm{C}$ occurs when a jump is detected in the call price but no jump is found in either the futures or the put price at the same time. Each of combination $\mathrm{C}$ and combination $\mathrm{P}$ account for $22 \%$ to $24 \%$ of the combinations for the three higher significance levels. In contrast, the frequency of the CP jump combination is only $11 \%$; this combination occurs when contemporaneous jumps are detected in both the call and the put, without a futures jump. Combinations F, FC and FP all have low frequencies.

Panel B of Table 4 shows counts of price change direction combinations, for the $\mathrm{CP}$ and FCP jump combinations. When the futures price jumps up or down, the call price always jumps 
in the same direction and the put price always jumps in the opposite direction. When the two option prices jump, but a futures jump is not detected, we find that the call price jumps in the opposite direction to the put price in almost all cases. At the $0.1 \%$ significance level there are 88 FCP combinations and $34 \mathrm{CP}$ combinations, from which there are only 2 occasions when the call and put prices jump in the same direction. We conclude that the impact of jumps in prices dominates that of any jumps in volatility when the market determines option prices.

In the example shown in Figure 5, the detected call and put price jumps are both negative at the $0.1 \%$ significance level at $14: 52$ on September 15,2006 . These changes in the call and put prices in the same direction may result from a data issue. For instance, an unusual ask or bid price can lead to a large price change, followed by an almost equivalent opposite price change within a short period. Therefore, this evidence is not sufficiently strong to show the existence of an independent jump in volatility.

We consider three further sets of jump test results to confirm the robustness of the results in Table 4. Firstly, we consider at-the-money options with monthly and quarterly maturities, secondly we consider prices measured at the popular 5-minute frequency data, and thirdly we divide the sample period into low and high volatility periods. Table 5 shows the empirical results for the detected jumps for these three situations. Comparing Panels A1 and A2 shows that the numbers of detected jumps for the out-of-the-money options are slightly larger than those for at-the-money options. This may occur because out-of-the-money options are more sensitive to the impact of unexpected events or news announcements.

Compared with the low-volatility period, the high-volatility period has relatively high percentages of the CP and FCP jump combinations, and relatively low percentages of the C and $\mathrm{P}$ jump combinations. The empirical results for the 5-minute frequency data are similar to those for the 3.5-minute frequency. As should be expected, we detect more jumps when returns are calculated over the shorter time intervals of 3.5 minutes and, consequently, a higher percentage of FCP events.

For the FCP jump combinations, the directions of futures jumps and call jumps are always the same, whereas the directions of put jumps are always opposite to those of futures jumps. There are two possible explanations for this observation. The first is that jumps in the 
(underlying asset) price exist whereas jumps in volatility do not. The second is that jumps in futures prices and in volatility can occur concurrently, with the impact on options prices of jumps in futures prices dominating that of jumps in volatility. The results for the CP and FCP jump combinations presented in Tables 4 and 5 cannot be interpreted as evidence for the existence of jumps in volatility.

\section{DETECTED JUMP COMBINATIONS FOR AFFINE PROCESSES}

The results obtained from our futures and options prices show no evidence for the existence of independent volatility jumps. We now attempt to recreate the observed jump statistics by using the affine jump-diffusion processes introduced in Section 3.1. The main objective is to examine whether the observed jump patterns can be explained by contemporaneous jumps in price and volatility or simply by jumps in prices.

The ABD test is conducted to detect jumps in theoretical futures and options prices obtained from simulated affine jump-diffusion processes. Section 5.1 explains the selection of the model parameters. Section 5.2 then presents additional insights into price dynamics gleaned from a comparison between the empirical FTSE-100 results and the simulated results for affine processes.

\subsection{Parameter selection}

A variety of econometric methods have been used to estimate the parameters of affine jumpdiffusion models (henceforth AJD). Pan (2002) used an implied-state generalized method of moments, while Eraker, Johannes, and Polson (2003) performed likelihood-based estimation with Markov chain Monte Carlo methods. Chernov et. al. (CGGT) (2003) used an efficient method of moments. Broadie, Chernov, and Johannes (2007) minimized the differences between model-based and market-based implied volatility. In this study, we aim to minimize the differences between AJD results and our empirical results in Table 4 for the detected jump numbers and the percentages of jump combinations. A deep out-of-the-money option is used to isolate the jump risk and to estimate the parameters of the AJD stochastic volatility models 
by Bates (2000), Pan (2002), and Eraker (2004). For high liquidity and similarity of empirical results with other sets of options, we focus on the results for the out-of-the-money option with monthly expiration. Therefore, in the simulations, we allow the expiration time to decrease repeatedly from 25 to 6 trading days.

Panel A of Table 6 lists the values of the parameters selected for simulating four AJD processes, namely the SV, SVJP, SVIJ and SVCJ processes. We follow a two-step selection methodology. First, we estimate risk-neutral parameters by minimizing the sum of the squares of the errors between the theoretical prices of Duffie, Pan, and Singleton (2000) and the 7minute frequency out-of-the-money option prices during the period between 8:06 and 16:30. The medians of monthly estimated parameters are shown in Panel B of Table 6, and can be seen to be of similar magnitudes to those obtained by Pan (2002). We use the estimates of $V_{0}, \tilde{\kappa}$, $\theta$, and $\xi$, but alter the other risk-neutral parameters.

Second, we choose the remaining real-world and risk-neutral parameters to try and match the simulated statistics for the jump combinations with the empirical estimates, guided when possible by parameter estimates from prior literature. In particular, the annual jump intensities in our simulations range from 2,000 to 3,000. These high numbers are necessary (1) because the high-frequency jump tests detect far more jumps than are estimated in the low-frequency literature which models daily prices, (2) because the jump tests have low power as already shown in Table 3.

The initial futures prices are set as $S_{0}=5475$ each day. The initial variance levels $\left(V_{0}\right)$ are $0.01,0.02$ and 0.05 , corresponding to $10 \%, 14 \%$ and $22 \%$ annual volatility for the lowvolatility, full-sample and high-volatility periods. The risk-free rate $r$ is set as $3 \%$.

Our annual equity risk premium is set to approximately $6 \%, 12 \%$ and $18 \%$ over the three periods, similar to the study by Pan (2002). ${ }^{7}$ The annualized diffusive volatility risk premium, $\tilde{\kappa}-\kappa$, is set as -0.25 , similar to the value obtained by Chernov and Ghysels (2000). In the SVCJ model for the full sample period, $\kappa$ and $\tilde{\kappa}$ are 7.25 and 7 , respectively; these values correspond to half-life values of $24.1(=252 \times \ln (2) / \kappa)$ and 25 trading days, respectively. 
To ensure that the detected numbers of simulated jump combinations are similar for $\mathrm{P}+$ and $\mathrm{FCP}(--+)$ to those of $\mathrm{P}-$ and $\mathrm{FCP}(++-)$, as seen empirically in Table 4 , we set $\rho$ to be equal to -0.01 , which is different from the values estimated by Eraker (2004) (-0.46) and Pan (2002) (approximately -0.5) from daily data.

Panel B of Table 6 comapres our risk-neutral parameters for the SVCJ process with the estimates reported by Pan (2002), CGGT (2003), Eraker, Johannes, and Polson (2003), Eraker (2004), and Wang (2009). Our means and standard deviations for the jump distributions are smaller than the earlier estimates because our high-frequency focus requires us to select high values for the jump intensities.

\subsection{AJD simulation results}

The jump results for simulations are now compared with the empirical results for 808 days of prices for the FTSE 100 index, and inferences are made about jumps in prices, jumps in volatility, and the related risk premia.

\subsubsection{Stochastic volatility without jumps}

The SV model has no jump component in either the price or variance processes. Panel A of Table 7 shows that the ABD test falsely claims slightly more jumps than predicted by the nominal significance level, with approximately 12 futures, 13 call and 13 put jumps detected every 808 days at the $1 \%$ daily significance level. The small number of jumps observed eliminates the SV model as a candidate to describe the much larger number of detected empirical jumps.

\subsubsection{Stochastic volatility with jumps in prices alone}

The SVJP model has a jump component in the stochastic differential equation defining futures prices but no jumps in the variance s.d.e. 
Panel C1 of Table 7 shows that the SVJP results detect numbers of jumps which are similar to the numbers for the empirical data shown in Panel B. For example, at the $0.1 \%$ significance level there are 150 detected empirical futures jumps and 165 detected simulated futures jumps (on average), during the same time period, with counts of 217 and 257 for detected call jumps, and 228 and 241 for detected put jumps. The percentages of jump combinations are similar for C, P, CP, FC and FP. However, the simulated percentages are notably lower for F and notably higher for FCP; thus when a futures jump is detected it is more likely in the simulation that call and put jumps will also be detected ${ }^{8}$. For combination CP, the detected simulated call and put jumps are always in opposite directions as nearly always occurs for the empirical results.

Panels C2 to C4 provide results when some of the risk premia are set to zero. There are only minor changes when the intensity premium is zero (Panel C2). Assuming there are no premia for the jumps does have a notable impact: the numbers of detected option jumps fall slightly, as do the percentages for the C, P and CP combinations (Panel C3).

Panel C5 shows the simulation results for the parameters estimated by Pan (2002). The low jump intensity and the high magnitude of jump sizes, relative to our preferred parameters, explains why (1) many fewer jumps are detected, (2) the numbers of detected jumps do not double when the significance level is multiplied by 10, and (3) the percentages of the FCP jump combinations are very high. These results support our selection of a high jump intensity.

\subsubsection{Stochastic volatility with independent jumps in price and in volatility}

Panel D of Table 7 shows similar results to Panel C1. Small and frequent independent jumps in volatility are not detected in these simulations, as we do not detect jumps in the call and put prices in the same direction.

\subsubsection{Stochastic volatility with contemporaneous jumps in price and in volatility}

The SVCJ simulation results in Table 8 are similar to the SVJP results in Panel C of Table 7. There are only minor differences, for the parameters selected in Table 6, because Panel B1 of 
Table 8 is almost identical to Panel $\mathrm{C} 1$ of Table 7. Again, the price jump risk premia and only these premia are necessary to match the numbers of detected option jumps, since there is a good match in Panel B2 of Table 8 but not in Panels B3, B4 and B5. Thus price jumps and price jump risk premia are sufficient to explain our empirical results. Nevertheless, contemporaneous volatility jumps can also be part of a successful explanation but they do not appear to be necessary.

Panels B6 and B7 of Table 8 show the impact of choosing a low jump intensity, below 2 per annum, respectively based upon the parameters of CGGT (2003) and our estimates in Panel B of Table 6 . These parameter choices are clearly not viable, because the numbers of detected jumps are very low. Calls and puts often jump in the same direction for our estimates (see Panel B7), showing that large jumps in volatility can be detected providing the intensity of the contemporaneous jumps is very low.

Finally, Panels B and C of Table 8 compare the empirical and simulated jump results for the low and high volatility periods. These comparisons show that our conclusions for the full sample period apply to both low and high volatility periods.

\section{CONCLUSIONS}

By studying prices recorded every three-and-a-half minutes we have found conclusive evidence firstly for jumps in futures prices and secondly for jumps in the prices of options written on the underlying futures asset. Our methodology also has the potential to detect jumps in the volatility of the underlying asset price, providing these are large enough to move call and put prices in the same direction regardless of any contemporaneous jump in the futures price. We find, however, that the impact of jumps in futures prices dominates that of any jumps in volatility when the market determines option prices. It is possible, but not proven, that volatility jumps coincide with jumps in futures prices which prevent us seeing call and put prices moving in the same direction. There is certainly no evidence for volatility jumps at those times when the futures prices do not jump. 
More jumps are detected in our option prices than in our futures prices. Simulation of affine jump-diffusion processes, containing either price jumps alone (the SVJP model) or contemporaneous price and volatility jumps (the SVCJ model), shows that we can explain the additional detected option price jumps if we select the model parameters appropriately. To do so it is necessary to incorporate jump risk premia, such that the risk-neutral distribution of price jumps has a mean and variance different to the real-world distribution. The high-frequency tests detect far more jumps than earlier studies reliant on daily and less frequent price observations. Consequently, a high jump intensity combined with generally small jumps is required to match our empirical results with those obtained from the AJD simulations. [WM3] 


\section{REFERENCES}

Andersen, T.G., \& Bollerslev, T. (1998). Answering the skeptics: yes, standard volatility models do provide accurate forecasts. International Economic Review, 39, 885-905.

Andersen, T.G., Bollerslev, T., \& Dobrev, D. (2007). No-arbitrage semi-martingale restrictions for continuous-time volatility models subject to leverage effects, jumps and i.i.d. noise: Theory and testable distribution implications. Journal of Econometrics, 138, 125-180.

Areal, N.M.P.C., \& Taylor, S.J. (2002). The realized volatility of FTSE-100 futures prices. Journal of Futures Markets, 22, 627-648.

Audrino, F., \& Fengler, M.R. (2015). Are classical option pricing models consistent with observed option second-order moments? Evidence from high-frequency data. Journal of Banking and Finance, 61, 46-63.

Barndorff-Nielsen, O.E., \& Shephard, N. (2001). Ornstein-Uhlenbeck based models and some of their uses in financial economics. Journal of the Royal Statistical Society, B63, 167-241.

Barndorff-Nielsen, O.E., \& Shephard, N. (2004). Power and bipower variation with stochastic volatility and jumps. Journal of Financial Econometrics, 2, 1-37.

Barndorff-Nielsen, O.E., \& Shephard, N. (2006). Econometrics of testing for jumps in financial economics using bipower variation. Journal of Financial Econometrics, 4, 1-30.

Bates, D.S. (1996). Jumps and stochastic volatility: Exchange rate processes implicit in Deutschemark options. Review of Financial Studies, 9, 69-107.

Bates, D.S. (2000). Post-'87 crash fears in the S\&P 500 futures options market. Journal of Econometrics, 94, 181-238.

Bollerslev, T., \& Todorov, V. (2011). Tails, fears, and risk premia. Journal of Finance, 66, 2165-2211.

Bollerslev, T., Law, T., \& Tauchen, G. (2008). Risk, jumps, and diversification. Journal of Econometrics, 144, 234-256.

Broadie, M., Chernov, M., \& Johannes, M. (2007). Model specification and risk premia: Evidence from futures options. Journal of Finance, 62, 1453-1490. 
Branger, N., Hansis, A.,\& Schlag, C. (2010). Expected option returns and the structure of jump risk premia. Working paper, University of Muenster.

Carr, P., \& Wu, L. (2009). Variance risk premiums. Review of Financial Studies, 22, 13111341.

Chernov, M., \& Ghysels, E. (2000). A study towards a unified approach to the joint estimation of objective and risk neutral measures for the purpose of options valuation. Journal of Financial Economics, 56, 407-458.

Chernov, M., Gallant, A.R., Ghysels, E., \& Tauchen, G.E. (2003). Alternative models for stock price dynamics. Journal of Econometrics, 16, 225-257.

Comte, F.,\& Renault, E. (1998). Long memory in continuous time stochastic volatility models. Mathematical Finance, 8, 291-323.

Duffie, D., Pan, J., \& Singleton, K.J. (2000). Transform analysis and asset pricing for affine jump-diffusions. Econometrica, 68, 1343-1376.

Eraker, B. (2004). Do stock prices and volatility jump? Reconciling evidence from spot and option prices. Journal of Finance, 59, 1367-1403.

Eraker, B., Johannes, M., \& Polson, N.G. (2003). The impact of jumps in returns and volatility. Journal of Finance, 53, 1269-1300.

Heston, S.L. (1993). A closed-form solution for options with stochastic volatility with applications to bond and currency options. Review of Financial Studies, 6, 327-343.

Kapetanios, G., Neumann, M., \& Skiadopoulos, G. (2014). Jumps in option prices and their determinants: Real-time evidence from the E-mini S\&P 500 option market. Working paper, Queen Mary, University of London.

Pan, J. (2002). The jump-risk premia implicit in options: Evidence from an integrated timeseries study. Journal of Financial Economics, 63, 3-50.

Taylor, S.J. (2010). An econometric defence of pure-jump price dynamics. Working Paper, Lancaster University.

Taylor, S.J. \& Xu, X. (1997). The incremental volatility information in one million foreign exchange quotations. Journal of Empirical Finance, 4, 317-340. 
Todorov, V. (2010). Variance risk-premium dynamics: The role of jumps. Review of Financial Studies, 23, 345-383.

Todorov, V., \& Tauchen, G.E. (2010). Activity signature functions for high-frequency data analysis. Journal of Econometrics, 154, 125-138.

Todorov, V., \& Tauchen, G.E. (2011). Volatility jumps. Journal of Business and Economic Statistics, 29 (3), 356-371.

Wang, Y.-H. (2009). The impact of jump dynamics on the predictive power of option-implied densities. Journal of Derivatives, 16 (3), 9-22.

Yun, J. (2014). Out-of-sample density forecasts with affine jump diffusion models. Journal of Banking and Finance, 47, 74-87. 
A. 0.25 -min frequency

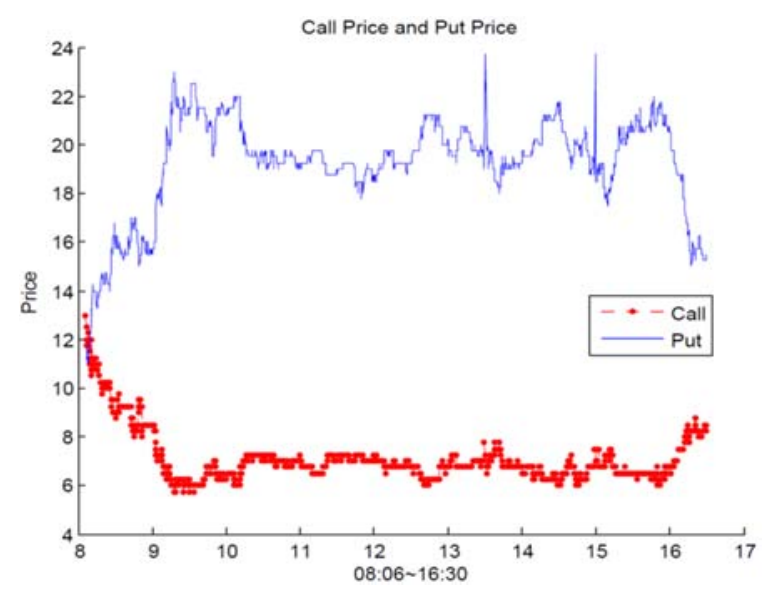

C. 3.5-min frequency

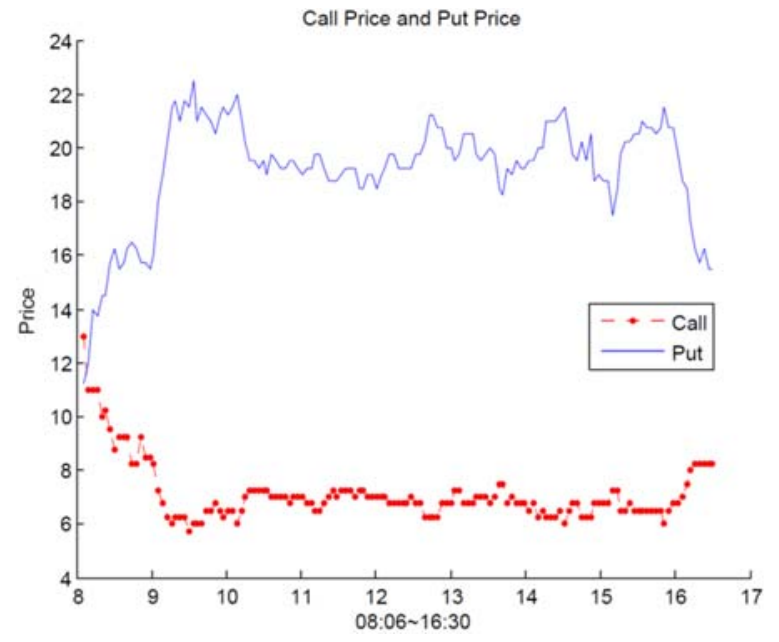

B. Futures 0.25 -min frequency

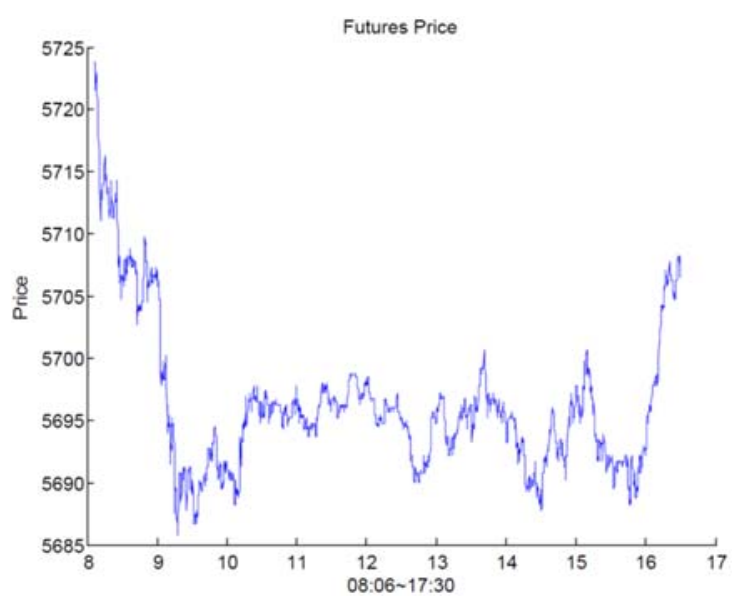

D. 5-min frequency

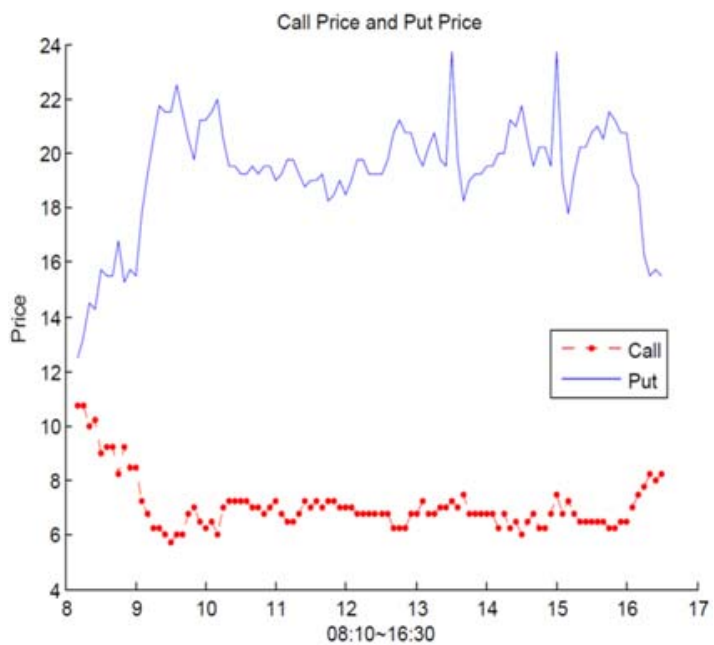

The prices commence at 8:06 in Panels A, B and C. They commence at 8:10 in Panel D.

FIGURE 1 The out-of-the-money options prices on January 13, 2006 
A. Monthly ATM Options

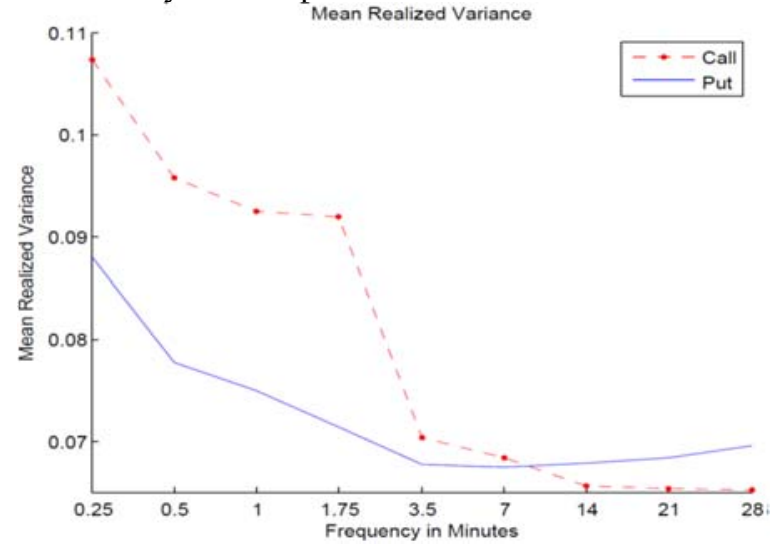

C. Quarterly ATM Options

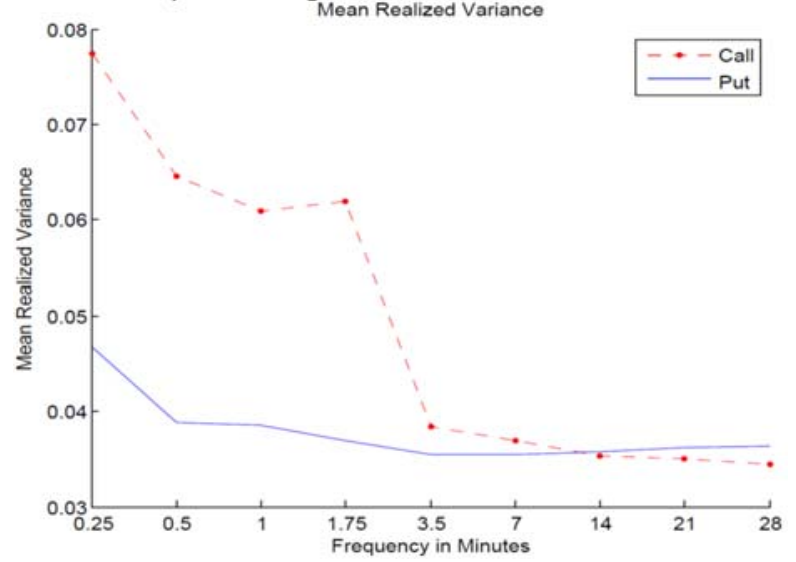

B. Monthly OTM Options

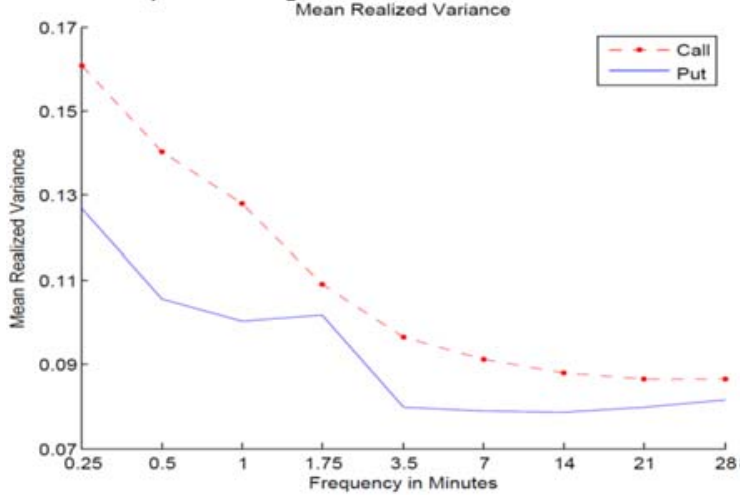

D. Futures

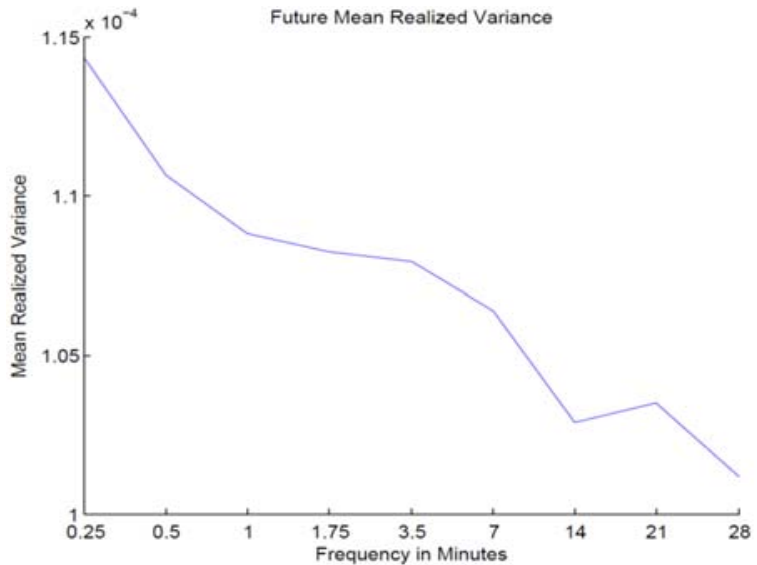

The first price used for each day is at 8:06. The three options series used for Panels A, B and C are defined in Section 4.1. The dashed line shows the mean realized variance of call prices. The solid lines show the mean realized variance of put and futures prices. Note the frequency scale is not linear.

FIGURE 2 Volatility signature plots: the mean realized variance during the period between $8: 06$ and $16: 30$ 
A. Monthly OTM Options

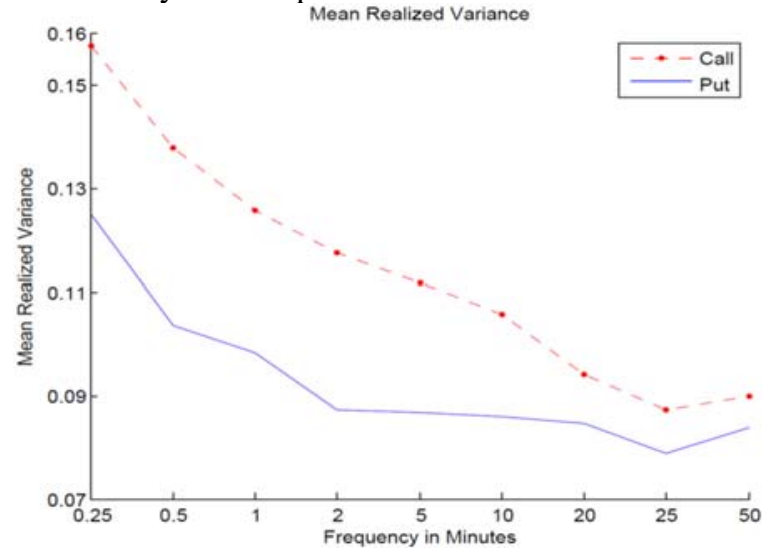

B. Futures

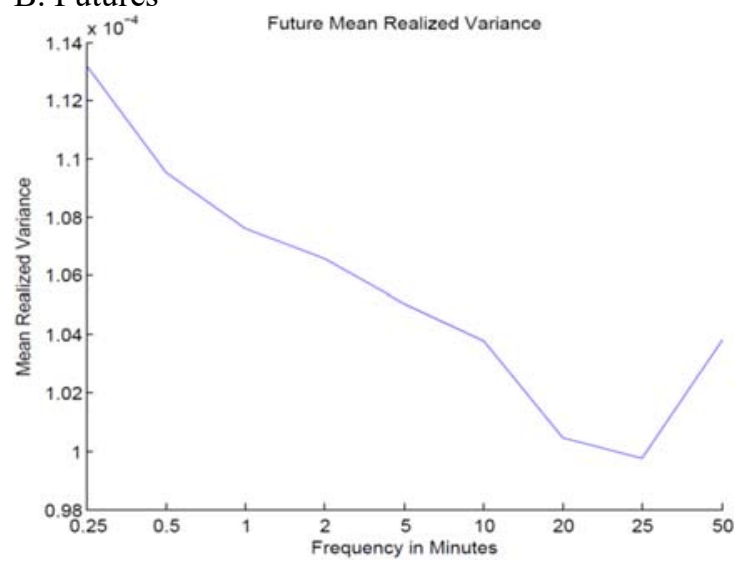

The first price used for each day is at 8:10. The dashed line shows the mean realized variance of call prices. The solid lines show the mean realized variance of put and futures prices. Note the frequency scale is not linear.

FIGURE 3 The mean realized variance during the period between 8:10 and 16:30 
A. Monthly ATM

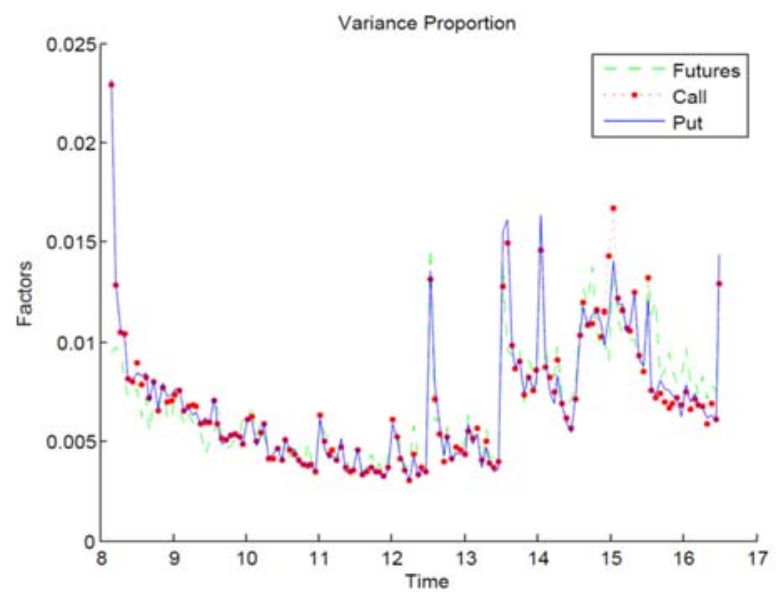

C. Quarterly ATM

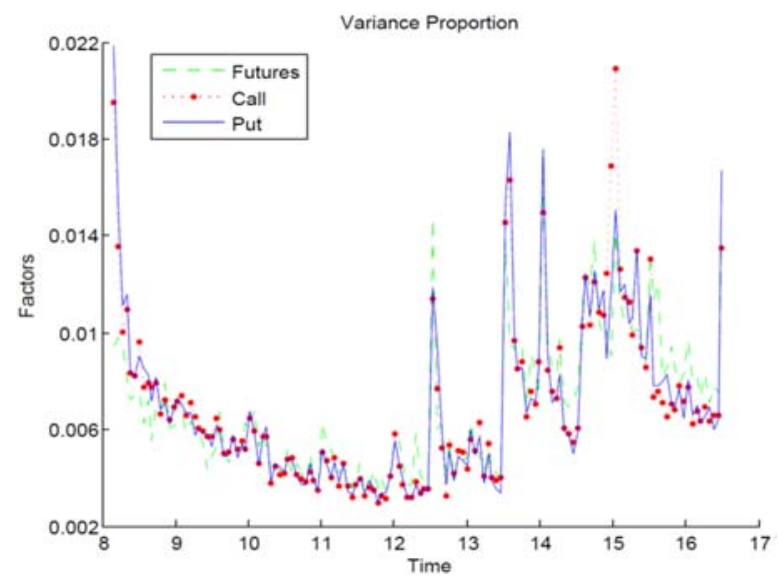

B. Monthly OTM

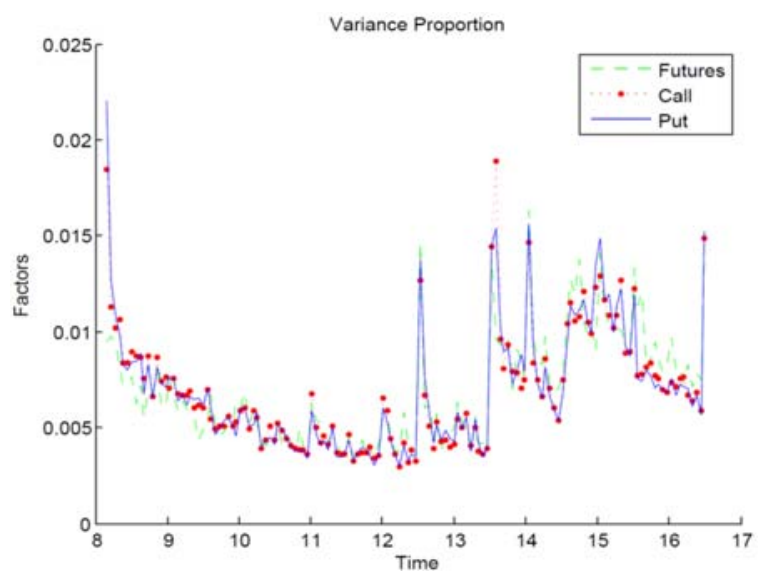

The variance proportion $f_{j}$ for the $j$-th intraday period is defined by Taylor and Xu (1997) and calculated from intraday returns $r_{d, j}$ as: $f_{j}=\frac{\sum_{d=1}^{T} r_{d, j}^{2}}{\sum_{d=1}^{T} \sum_{j=1}^{m} r_{d, j}^{2}}$. The dashed line denotes the variance proportion for futures, the dotdashed line denotes that of call prices and the solid line denotes that of put prices. The first price used for each day is at 8:06.

FIGURE 4 Estimates of the variance proportions when the data frequency is 3.5 -minutes 
A.

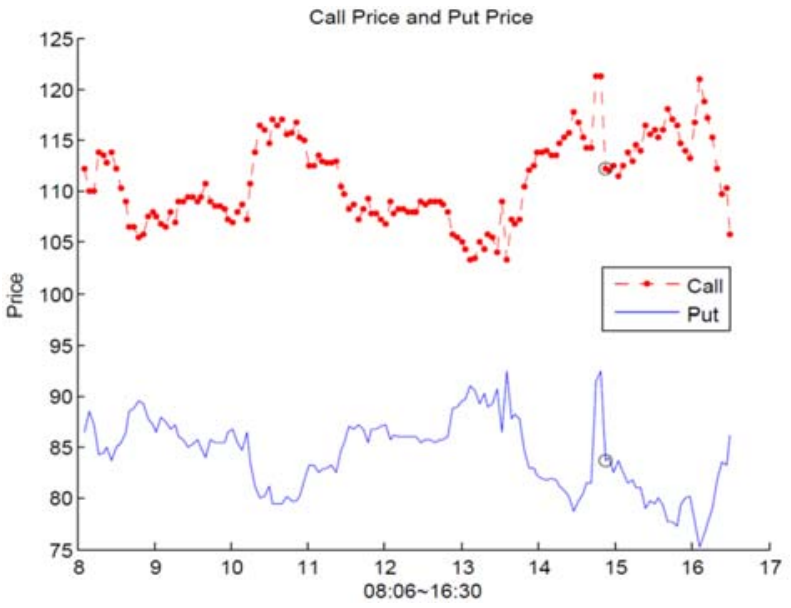

B.

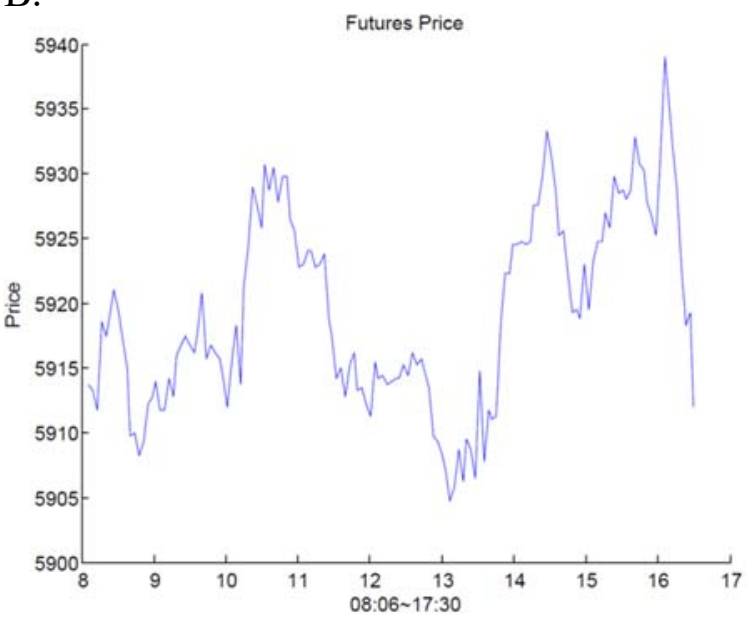

The small circles denote the detected jumps in the call price and the put price at 14:52.

FIGURE 5 Futures and monthly out-of-the-money options prices with 3.5-min frequency on September 15, 2006 
TABLE 1The size of the ABD test applied to futures, call and put prices when futures prices are determined by geometric Brownian motion

\begin{tabular}{|c|c|c|c|c|c|c|c|c|c|c|c|c|c|}
\hline \multirow[b]{2}{*}{$\alpha(\%)$} & \multicolumn{4}{|c|}{ Futures } & & \multicolumn{4}{|c|}{ Call } & \multicolumn{4}{|c|}{ Put } \\
\hline & 1 & .1 & .01 & .001 & $\underline{S} \underline{\partial C}$ & 1 & .1 & .01 & .001 & 1 & .1 & .01 & .001 \\
\hline$K / S$ & $\begin{array}{l}\text { e.s. } \\
(\%)\end{array}$ & $\begin{array}{l}\text { e.s. } \\
(\%)\end{array}$ & $\begin{array}{l}\text { e.s. } \\
\text { (\%) }\end{array}$ & $\begin{array}{l}\text { e.s. } \\
(\%)\end{array}$ & & $\begin{array}{l}\text { e.s. } \\
(\%)\end{array}$ & $\begin{array}{l}\text { e.s. } \\
(\%)\end{array}$ & $\begin{array}{l}\text { e.s. } \\
\text { (\%) }\end{array}$ & $\begin{array}{l}\text { e.s. } \\
(\%)\end{array}$ & $\begin{array}{l}\text { e.s. } \\
(\%)\end{array}$ & $\begin{array}{l}\text { e.s. } \\
\text { (\%) }\end{array}$ & $\begin{array}{l}\text { e.s. } \\
(\%)\end{array}$ & $\begin{array}{l}\text { e.s. } \\
(\%)\end{array}$ \\
\hline
\end{tabular}

\begin{tabular}{|c|c|c|c|c|c|c|c|c|c|c|c|c|c|}
\hline \multicolumn{14}{|c|}{ A. average volatility level } \\
\hline & 1.27 & 0.15 & 0.018 & 0.0025 & & & & & & & & & \\
\hline 1.02 & & & & & 43 & 1.54 & 0.20 & 0.027 & 0.0055 & 1.64 & 0.23 & 0.032 & 0.0075 \\
\hline 1 & & & & & 37 & 1.59 & 0.21 & 0.029 & 0.0055 & 1.60 & 0.22 & 0.033 & 0.0065 \\
\hline 0.98 & & & & & 29 & 1.63 & 0.22 & 0.028 & 0.0055 & 1.57 & 0.21 & 0.030 & 0.0055 \\
\hline \multicolumn{14}{|c|}{ B. low volatility } \\
\hline & 1.27 & 0.15 & 0.018 & 0.0025 & & & & & & & & & \\
\hline 1.02 & & & & & 62 & 1.53 & 0.20 & 0.026 & 0.0060 & 1.64 & 0.23 & 0.032 & 0.0075 \\
\hline 1 & & & & & 49 & 1.60 & 0.21 & 0.029 & 0.0055 & 1.60 & 0.22 & 0.033 & 0.0060 \\
\hline 0.98 & & & & & 36 & 1.64 & 0.22 & 0.028 & 0.0060 & 1.55 & 0.20 & 0.029 & 0.0055 \\
\hline \multicolumn{14}{|c|}{ C. high volatility } \\
\hline & 1.27 & 0.15 & 0.018 & 0.0025 & & & & & & & & & \\
\hline 1.02 & & & & & 25 & 1.56 & 0.21 & 0.027 & 0.0055 & 1.63 & 0.23 & 0.032 & 0.0075 \\
\hline 1 & & & & & 23 & 1.59 & 0.21 & 0.029 & 0.0055 & 1.61 & 0.22 & 0.032 & 0.0065 \\
\hline 0.98 & & & & & 20 & 1.62 & 0.22 & 0.029 & 0.0050 & 1.58 & 0.21 & 0.032 & 0.0060 \\
\hline
\end{tabular}

The tabulated numbers are estimates of the daily size (denoted e.s.) of a test for jumps in asset prices. Annual volatility is equal to $14 \%, 10 \%$, and $22 \%$ in Panels A, B and C respectively. $K$ and $S$ respectively denote the strike and futures prices. Time to expiry of the options repeatedly decreases from 25 to 6 days, during a simulation period of 200,000days. There are 144 time steps per day. The column headed $(S / C)(\partial C / \partial S)$ lists average values. 
TABLE 2 The size and power of the ABD test for futures and options prices, for the SV, SVJP, and SVIJ processes

\begin{tabular}{|c|c|c|c|c|c|c|c|c|c|}
\hline \multirow[b]{2}{*}{ Price } & \multirow{2}{*}{$\begin{array}{l}\alpha \\
\text { Moneyness } \\
(K / S)\end{array}$} & \multicolumn{2}{|c|}{$1 \%$} & \multicolumn{2}{|c|}{$0.1 \%$} & \multicolumn{2}{|c|}{$0.01 \%$} & \multicolumn{2}{|c|}{$0.001 \%$} \\
\hline & & size & power & size & power & size & power & size & Power \\
\hline \multicolumn{10}{|c|}{ A. SV model } \\
\hline \multirow[t]{2}{*}{ Fut. } & & 1.51 & - & 0.19 & - & 0.031 & - & 0.0055 & - \\
\hline & 1.02 & 1.58 & - & 0.23 & - & 0.043 & - & 0.0150 & - \\
\hline \multirow[t]{3}{*}{ Call } & 1 & 1.65 & - & 0.23 & - & 0.035 & - & 0.0040 & - \\
\hline & 0.98 & 1.75 & - & 0.24 & - & 0.035 & - & 0.0050 & - \\
\hline & 1.02 & 1.73 & - & 0.25 & - & 0.038 & - & 0.0095 & - \\
\hline \multirow[t]{2}{*}{ Put } & 1 & 1.64 & - & 0.21 & - & 0.032 & - & 0.0065 & - \\
\hline & 0.98 & 1.63 & - & 0.23 & - & 0.056 & - & 0.0195 & - \\
\hline \multicolumn{10}{|c|}{ B. SVJP model } \\
\hline \multirow[t]{2}{*}{ Fut. } & & 0.63 & 4.32 & 0.08 & 2.36 & 0.013 & 1.35 & 0.0021 & 0.81 \\
\hline & 1.02 & 0.58 & 6.51 & 0.07 & 3.86 & 0.006 & 2.36 & 0.0005 & 1.50 \\
\hline \multirow[t]{3}{*}{ Call } & 1 & 0.59 & 6.86 & 0.07 & 4.11 & 0.007 & 2.53 & 0.0005 & 1.61 \\
\hline & 0.98 & 0.61 & 6.98 & 0.07 & 4.20 & 0.012 & 2.62 & 0.0011 & 1.68 \\
\hline & 1.02 & 0.64 & 6.13 & 0.07 & 3.62 & 0.013 & 2.22 & 0.0011 & 1.42 \\
\hline \multirow[t]{2}{*}{ Put } & 1 & 0.64 & 5.58 & 0.07 & 3.24 & 0.015 & 1.96 & 0.0016 & 1.24 \\
\hline & 0.98 & 0.64 & 4.78 & 0.07 & 2.70 & 0.013 & 1.61 & 0.0005 & 1.00 \\
\hline \multicolumn{10}{|c|}{ C. SVIJ model } \\
\hline \multirow[t]{2}{*}{ Fut. } & & 0.62 & 4.18 & 0.07 & 2.27 & 0.009 & 1.30 & 0.0011 & 0.78 \\
\hline & 1.02 & 0.54 & 0.47 & 0.06 & 0.26 & 0.004 & 0.16 & 0.0005 & 0.10 \\
\hline \multirow[t]{3}{*}{ Call } & 1 & 0.55 & 0.48 & 0.06 & 0.27 & 0.006 & 0.17 & 0.0005 & 0.10 \\
\hline & 0.98 & 0.55 & 0.49 & 0.06 & 0.28 & 0.006 & 0.17 & 0.0005 & 0.11 \\
\hline & 1.02 & 0.55 & 0.48 & 0.06 & 0.28 & 0.005 & 0.16 & 0.0000 & 0.10 \\
\hline \multirow[t]{2}{*}{ Put } & 1 & 0.54 & 0.47 & 0.06 & 0.27 & 0.005 & 0.16 & 0.0000 & 0.10 \\
\hline & 0.98 & 0.54 & 0.45 & 0.06 & 0.25 & 0.004 & 0.15 & 0.0000 & 0.09 \\
\hline
\end{tabular}

The daily size and power estimates are all percentages. The stochastic processes are defined in Section 3.1. Their parameter values are listed in Table 6, Panel A, which are estimates obtained from FTSE contracts for the period from 2005 to 2009 . There are 200,000 days in each simulation and 144 time steps in each day. $K$ and $S$ respectively denote the strike and futures prices. 
TABLE 3 The size and power of the ABD test for futures and options prices, for the SVCJ model

\begin{tabular}{|c|c|c|c|c|c|c|c|c|c|}
\hline \multirow[b]{2}{*}{ Price } & \multirow{2}{*}{$\begin{array}{l}{ }^{\alpha} \\
\left.\text { Moneyness }^{\alpha} / S\right)\end{array}$} & \multicolumn{2}{|c|}{$1 \%$} & \multicolumn{2}{|c|}{$0.1 \%$} & \multicolumn{2}{|c|}{$0.01 \%$} & \multicolumn{2}{|c|}{$0.001 \%$} \\
\hline & & size & power & Size & power & size & power & size & power \\
\hline \multicolumn{10}{|c|}{ A. full sample parameters } \\
\hline \multirow[t]{2}{*}{ Index } & & 0.51 & 7.77 & 0.05 & 4.81 & 0.004 & 3.07 & 0.0005 & 2.02 \\
\hline & 1.02 & 0.47 & 9.40 & 0.05 & 6.05 & 0.005 & 4.00 & 0.0005 & 2.71 \\
\hline \multirow[t]{3}{*}{ Call } & 1 & 0.48 & 9.98 & 0.05 & 6.49 & 0.005 & 4.34 & 0.0005 & 2.97 \\
\hline & 0.98 & 0.52 & 10.29 & 0.05 & 6.74 & 0.005 & 4.53 & 0.0005 & 3.12 \\
\hline & 1.02 & 0.53 & 10.10 & 0.06 & 6.60 & 0.009 & 4.44 & 0.0005 & 3.04 \\
\hline \multirow[t]{2}{*}{ Put } & 1 & 0.50 & 9.69 & 0.06 & 6.27 & 0.007 & 4.18 & 0.0005 & 2.84 \\
\hline & 0.98 & 0.49 & 9.00 & 0.05 & 5.74 & 0.007 & 3.77 & 0.0016 & 2.54 \\
\hline \multicolumn{10}{|c|}{ B. low volatility parameters } \\
\hline \multirow[t]{2}{*}{ Index } & & 0.69 & 7.24 & 0.08 & 4.45 & 0.011 & 2.82 & 0.0005 & 1.84 \\
\hline & 1.02 & 0.60 & 8.15 & 0.07 & 5.06 & 0.010 & 3.22 & 0.0019 & 2.12 \\
\hline \multirow[t]{3}{*}{ Call } & 1 & 0.56 & 11.21 & 0.06 & 7.47 & 0.007 & 5.08 & 0.0000 & 3.55 \\
\hline & 0.98 & 0.57 & 14.12 & 0.07 & 9.81 & 0.007 & 6.97 & 0.0005 & 5.02 \\
\hline & 1.02 & 0.56 & 13.86 & 0.06 & 9.60 & 0.008 & 6.77 & 0.0016 & 4.89 \\
\hline \multirow[t]{2}{*}{ Put } & 1 & 0.54 & 10.74 & 0.06 & 7.08 & 0.008 & 4.80 & 0.0005 & 3.32 \\
\hline & 0.98 & 0.65 & 7.49 & 0.07 & 4.56 & 0.015 & 2.87 & 0.0044 & 1.85 \\
\hline \multicolumn{10}{|c|}{ C. high volatility parameters } \\
\hline \multirow[t]{2}{*}{ Index } & & 0.39 & 5.51 & 0.05 & 3.23 & 0.003 & 1.97 & 0.0005 & 1.25 \\
\hline & 1.02 & 0.40 & 7.20 & 0.05 & 4.46 & 0.003 & 2.86 & 0.0000 & 1.87 \\
\hline \multirow[t]{3}{*}{ Call } & 1 & 0.41 & 7.31 & 0.05 & 4.53 & 0.003 & 2.92 & 0.0000 & 1.91 \\
\hline & 0.98 & 0.42 & 7.38 & 0.05 & 4.59 & 0.003 & 2.96 & 0.0000 & 1.94 \\
\hline & 1.02 & 0.43 & 7.30 & 0.05 & 4.54 & 0.008 & 2.90 & 0.0005 & 1.92 \\
\hline \multirow[t]{2}{*}{ Put } & 1 & 0.41 & 7.22 & 0.05 & 4.47 & 0.008 & 2.85 & 0.0005 & 1.88 \\
\hline & 0.98 & 0.41 & 7.08 & 0.04 & 4.37 & 0.008 & 2.78 & 0.0005 & 1.83 \\
\hline
\end{tabular}

The daily size and power estimates are all percentages. The SVCJ stochastic process is defined in Section 3.1. The parameter values are listed in Table 6, Panel A; these are estimates obtained from FTSE contracts for the period from 2005 to 2009 . There are 200,000 days in each simulation and 144 time steps in each day. $K$ and $S$ respectively denote the strike and futures prices. 
TABLE 4 The detected jumps in futures and monthly out-of-the-money options prices Panel A Jumps and combinations

\begin{tabular}{|c|c|c|c|c|c|c|c|c|c|c|c|c|}
\hline \multirow{2}{*}{$\begin{array}{r}\alpha \\
(\%)\end{array}$} & \multicolumn{3}{|c|}{$\begin{array}{c}\text { Numbers of jumps } \\
\text { detected }\end{array}$} & \multicolumn{8}{|c|}{ Numbers of jump combinations } & \multirow{2}{*}{$\begin{array}{l}\text { Total jump } \\
\text { combinations }\end{array}$} \\
\hline & $\mathrm{F}$ & $\mathrm{C}$ & $\mathrm{P}$ & $\mathrm{C}$ & $\begin{array}{l}\mathrm{P} \\
+\end{array}$ & $\begin{array}{l}\mathrm{P} \\
-\end{array}$ & $\mathrm{CP}$ & $\mathrm{F}$ & $\mathrm{FC}$ & FP & FCP & \\
\hline 1 & 306 & 431 & 423 & 144 & 70 & 73 & 74 & 65 & 35 & 28 & 178 & 667 \\
\hline 0.1 & 150 & 217 & 228 & 74 & 41 & 41 & 36 & 21 & 19 & 22 & 88 & 342 \\
\hline 0.01 & 79 & 128 & 127 & 47 & 22 & 24 & 21 & 10 & 9 & 9 & 51 & 193 \\
\hline 0.001 & 45 & 65 & 90 & 22 & 21 & 19 & 15 & 6 & 4 & 11 & 24 & 122 \\
\hline \multicolumn{12}{|c|}{ Percentages of jump combinations } & \\
\hline 1 & & & & 22 & 10 & 11 & 11 & 10 & 5 & 4 & 27 & \\
\hline 0.1 & & & & 22 & 12 & 12 & 11 & 6 & 6 & 6 & 26 & \\
\hline 0.01 & & & & 24 & 11 & 12 & 11 & 5 & 5 & 5 & 26 & \\
\hline 0.001 & & & & 18 & 17 & 16 & 12 & 5 & 3 & 9 & 20 & \\
\hline
\end{tabular}

Rows 1 to 4 show the numbers of detected jumps and the numbers of jump combinations across different daily significance levels.

Columns 2 to 4 show the numbers of detected jumps in futures (F), calls $(\mathrm{C})$ and puts $(\mathrm{P})$. Columns 5 to 12 show how often jumps are detected for only the named securities, e.g. the heading $\mathrm{C}$ in column 5 refers to times when a jump is detected in the call but none is detected in the futures or the put, while FCP in column 12 refers to times when contemporaneous jumps are detected in the futures, the call and the put. Columns 6 and 7 , headed $\mathrm{P}+$ and $\mathrm{P}-$, respectively denote the numbers of positive and negative detected jumps in the put when no jumps are detected in the futures and the call.

Rows 5 to 8 show the percentages of jump combinations which are the numbers of specific jump combinations divided by the total numbers of jump combinations.

Panel B The components of the CP and FCP jump combinations

\begin{tabular}{|c|c|c|c|c|c|c|c|c|c|c|}
\hline \multicolumn{7}{|c|}{ Numbers of jump combinations } & \multirow[b]{2}{*}{$\begin{array}{l}\text { F C P } \\
++-\end{array}$} & \multirow[b]{2}{*}{$\begin{array}{l}\text { F C P } \\
--+\end{array}$} & \multirow[b]{2}{*}{$\begin{array}{l}\text { Other } \\
\text { FCP }\end{array}$} & \multirow[b]{2}{*}{$\begin{array}{l}\text { Total jump } \\
\text { combinations }\end{array}$} \\
\hline $\begin{array}{r}\alpha \\
(\%)\end{array}$ & $\begin{array}{l}\mathrm{CP} \\
+-\end{array}$ & $\begin{array}{c}\mathrm{CP} \\
-+\end{array}$ & $\begin{array}{l}\text { Sub- } \\
\text { total }\end{array}$ & $\begin{array}{l}\mathrm{CP} \\
++\end{array}$ & $\begin{array}{l}\mathrm{CP} \\
--\end{array}$ & $\begin{array}{l}\text { Sub- } \\
\text { total }\end{array}$ & & & & \\
\hline 1 & 33 & 38 & 71 & 2 & 1 & 3 & 79 & 99 & 0 & 667 \\
\hline 0.1 & 16 & 18 & 34 & 1 & 1 & 2 & 45 & 43 & 0 & 342 \\
\hline 0.01 & 11 & 9 & 18 & 0 & 1 & 1 & 24 & 27 & 0 & 193 \\
\hline 0.001 & 10 & 5 & 15 & 0 & 0 & 0 & 10 & 14 & 0 & 122 \\
\hline \multicolumn{7}{|c|}{ Percentages of jump combinations } & & & & \\
\hline 1 & 4.9 & 5.7 & $10.6^{\circ}$ & 0.3 & 0.1 & 0.4 & 11.8 & 14.8 & 0 & \\
\hline 0.1 & 4.7 & 5.3 & 9.9 & 0.3 & 0.3 & 0.6 & 13.2 & 12.6 & 0 & \\
\hline 0.01 & 5.7 & 4.7 & 9.3 & 0.0 & 0.5 & 0.5 & 12.4 & 14.0 & 0 & \\
\hline 0.001 & 8.2 & 4.1 & 12.3 & 0.0 & 0.0 & 0.0 & 8.2 & 11.5 & 0 & \\
\hline
\end{tabular}

Rows 1 to 4 are the numbers of jump combination across different daily significance levels. Rows 5 to 8 are the same numbers divided by the total numbers of jump combinations, as percentages.

The columns show numbers and percentages for when both the call and the put jump. For example, the column $\mathrm{CP}(+-)$ refers to contemporaneous positive detected jumps in calls and negative detected jumps in puts when no jump is detected in futures, while the column $\mathrm{FCP}(++-)$ refers to contemporaneous negative detected jumps in puts and positive detected jumps in both futures and calls. 
TABLE 5 Detected jumps in selected datasets of futures and options prices

\begin{tabular}{|c|c|c|c|c|c|c|c|c|c|c|c|c|c|c|c|}
\hline \multirow[t]{2}{*}{${ }_{(\%)}^{\alpha}$} & \multicolumn{3}{|c|}{$\begin{array}{l}\text { Detected jumps } \\
\text { per } 808 \text { days }\end{array}$} & \multicolumn{8}{|c|}{ Percentages of jump combinations } & \multirow[b]{2}{*}{$\mathrm{Cl}$} & \multirow[b]{2}{*}{ CI } & \multirow[b]{2}{*}{$\begin{array}{l}\text { CP } \\
++\end{array}$} & \multirow[b]{2}{*}{$\begin{array}{r}\mathrm{CP} \\
--\end{array}$} \\
\hline & $\mathrm{F}$ & $\mathrm{C}$ & $\mathrm{P}$ & $\mathrm{C}$ & $\begin{array}{l}\text { P } \\
+\end{array}$ & $\begin{array}{c}\mathrm{P} \\
-\end{array}$ & $\mathrm{CP}$ & $\mathrm{F}$ & $\mathrm{FC}$ & FP & $\mathrm{FCP}$ & & & & \\
\hline
\end{tabular}

Panel A. Full sample period from 2005 to 2009

A1. 3.5-min frequency, monthly out-of-the-money options prices

\begin{tabular}{rrrr|rrrrrrrr|rrrr}
1 & 306 & 431 & 423 & 22 & 10 & 11 & 11 & 10 & 5 & 4 & 27 & 4.9 & 5.7 & 0.3 & 0.1 \\
0.1 & 150 & 217 & 228 & 22 & 12 & 12 & 11 & 6 & 6 & 6 & 26 & 4.7 & 5.3 & 0.3 & 0.3 \\
0.01 & 79 & 128 & 127 & 24 & 11 & 12 & 11 & 5 & 5 & 5 & 26 & 5.7 & 4.7 & 0.0 & 0.5 \\
0.001 & 45 & 65 & 90 & 18 & 17 & 16 & 12 & 5 & 3 & 9 & 20 & 8.2 & 4.1 & 0.0 & 0.0
\end{tabular}

A2. 3.5-min frequency, monthly at-the-money options prices

\begin{tabular}{rrrr|rrrrrrrr|rrrr}
1 & 306 & 402 & 392 & 18 & 8 & 8 & 13 & 10 & 5 & 5 & 33 & 5.8 & 7.0 & 0.2 & 0.3 \\
0.1 & 150 & 192 & 194 & 15 & 13 & 6 & 14 & 11 & 6 & 3 & 32 & 7.0 & 5.9 & 0.3 & 0.3 \\
0.01 & 79 & 112 & 112 & 17 & 9 & 8 & 16 & 8 & 3 & 4 & 35 & 6.4 & 9.6 & 0.0 & 0.0 \\
0.001 & 45 & 71 & 70 & 18 & 8 & 9 & 19 & 4 & 6 & 5 & 31 & 9.3 & 9.3 & 0.0 & 0.0
\end{tabular}

A3. 3.5-min frequency, quarterly at-the-money options prices

\begin{tabular}{rrrr|rrrrrrrr|rrrr}
1 & 306 & 403 & 447 & 17 & 12 & 10 & 14 & 10 & 4 & 6 & 28 & 6.0 & 7.6 & 0.0 & 0.2 \\
0.1 & 150 & 206 & 220 & 17 & 14 & 8 & 15 & 10 & 5 & 4 & 28 & 7.5 & 7.2 & 0.0 & 0.3 \\
0.01 & 79 & 116 & 131 & 16 & 13 & 12 & 15 & 7 & 4 & 3 & 31 & 6.2 & 8.4 & 0.0 & 0.0 \\
0.001 & 45 & 76 & 82 & 18 & 11 & 13 & 18 & 4 & 5 & 5 & 28 & 9.0 & 9.0 & 0.0 & 0.0
\end{tabular}

A3. 5-min frequency, monthly out-of-the-money options prices

\begin{tabular}{rrrr|rrrrrrrr|rrrr}
1 & 205 & 364 & 356 & 27 & 11 & 15 & 12 & 7 & 5 & 4 & 20 & 6.3 & 5.4 & 0.3 & 0.2 \\
0.1 & 101 & 180 & 184 & 22 & 12 & 15 & 16 & 6 & 7 & 4 & 19 & 6.4 & 8.1 & 0.7 & 0.4 \\
0.01 & 50 & 105 & 103 & 28 & 13 & 15 & 14 & 7 & 4 & 2 & 16 & 8.9 & 4.7 & 0.6 & 0.0 \\
0.001 & 33 & 74 & 55 & 36 & 9 & 12 & 13 & 8 & 5 & 4 & 13 & 4.5 & 7.3 & 0.9 & 0.0 \\
\hline
\end{tabular}

Panel B. Low-volatility period from January 2005 to June 2007

B1. 3.5-min frequency, monthly out-of-the-money options prices

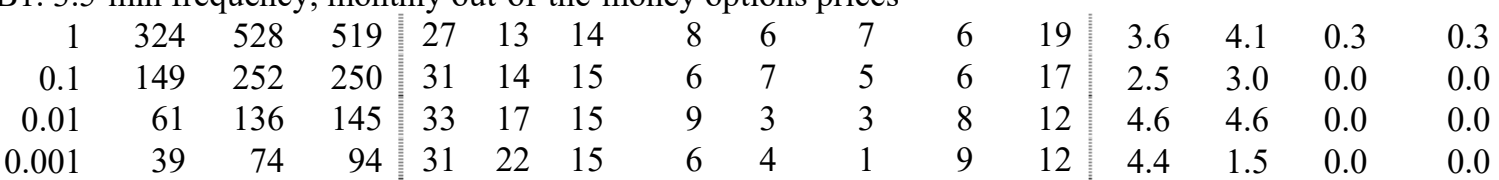

B2. 5-min frequency, monthly out-of-the-money options prices

\begin{tabular}{rrrr|rrrrrrrr|rrrr}
1 & 206 & 381 & 342 & 31 & 14 & 12 & 8 & 7 & 5 & 3 & 20 & 4.4 & 3.7 & 0.4 & 0.0 \\
0.1 & 81 & 208 & 184 & 34 & 13 & 16 & 12 & 1 & 6 & 3 & 15 & 5.6 & 5.6 & 0.7 & 0.0 \\
0.01 & 35 & 120 & 107 & 38 & 16 & 16 & 11 & 2 & 2 & 0 & 14 & 3.5 & 5.9 & 1.2 & 0.0 \\
0.001 & 20 & 85 & 79 & 40 & 19 & 17 & 10 & 2 & 2 & 0 & 11 & 1.6 & 6.3 & 1.6 & 0.0 \\
\hline
\end{tabular}

Panel C. High-volatility period from July 2007 to December 2009

C1. 3.5-min frequency, monthly out-of-the-money options prices

\begin{tabular}{rrrrrrrrrrrr|rrrr}
1 & 252 & 364 & 396 & 15 & 10 & 9 & 20 & 9 & 2 & 5 & 31 & 8.2 & 11.3 & 0.0 & 0.0 \\
0.1 & 123 & 180 & 204 & 15 & 11 & 12 & 17 & 9 & 2 & 3 & 30 & 6.6 & 10.6 & 0.0 & 0.0 \\
0.01 & 59 & 92 & 107 & 20 & 19 & 8 & 13 & 8 & 1 & 4 & 25 & 6.0 & 7.2 & 0.0 & 0.0 \\
0.001 & 29 & 39 & 70 & 17 & 17 & 20 & 11 & 0 & 0 & 17 & 17 & 2.2 & 8.7 & 0.0 & 0.0
\end{tabular}

C2. 5-min frequency, monthly out-of-the-money options prices

\begin{tabular}{rrrr|rrrrrrrr|rrr|r}
1 & 166 & 374 & 322 & 29 & 10 & 8 & 21 & 7 & 1 & 2 & 23 & 10.1 & 9.8 & 0.0 & 0.7 \\
0.1 & 85 & 193 & 171 & 28 & 13 & 9 & 20 & 6 & 4 & 2 & 19 & 10.7 & 9.4 & 0.0 & 0.0 \\
0.01 & 48 & 107 & 105 & 26 & 12 & 11 & 21 & 5 & 2 & 5 & 19 & 10.6 & 10.6 & 0.0 & 0.0 \\
0.001 & 28 & 59 & 63 & 21 & 8 & 13 & 27 & 6 & 2 & 6 & 17 & 10.4 & 16.7 & 0.0 & 0.0 \\
\hline
\end{tabular}

Columns 2 to 4 show the number of detected jumps per 808 days. There are 369 and 439 days respectively in the low- and high-volatility periods. Actual detections are multiplied by 808/369 in Panel B and by 808/439 in Panel C. See Table 4 for information about the column headings. 
TABLE 6 Estimated and selected parameters of affine jump-diffusion models

Panel A Parameters selected for Monte Carlo simulations

\begin{tabular}{|c|c|c|c|c|c|c|}
\hline Period & & Full sam & period & & Low volatility & High volatility \\
\hline Parameters & SV & SVJP & SVIJ & SVCJ & SVCJ & SVCJ \\
\hline$V_{0}$ & 0.022 & 0.02 & 0.02 & 0.02 & 0.01 & 0.05 \\
\hline$\gamma$ & $0.5 \%$ & $11.9 \%$ & $14.3 \%$ & $11.9 \%$ & $6.2 \%$ & $19.1 \%$ \\
\hline$\theta$ & 0.020 & 0.007 & 0.004 & 0.004 & 0.004 & 0.01 \\
\hline$\kappa$ & 4.65 & 6.25 & 7.25 & 7.25 & 7.25 & 7.05 \\
\hline$\tilde{\kappa}$ & 4.4 & 6.0 & 7.0 & 7.0 & 7.0 & 6.8 \\
\hline$\xi$ & 0.51 & 0.50 & 0.45 & 0.45 & 0.45 & 0.46 \\
\hline$\rho$ & -0.01 & -0.01 & -0.01 & -0.01 & -0.01 & -0.01 \\
\hline$\lambda^{p}$ & - & 2300 & 2300 & 2300 & 2000 & 3000 \\
\hline$\tilde{\lambda}^{p}$ & - & 2250 & 2250 & 2250 & 1980 & 2930 \\
\hline$\lambda^{V}$ & - & - & 2300 & 2300 & 2000 & 3000 \\
\hline$\tilde{\lambda}^{V}$ & - & - & 2250 & 2250 & 1980 & 2930 \\
\hline$\mu(* 0.0001)$ & - & -0.6 & -0.6 & -0.6 & -0.01 & -1 \\
\hline$\tilde{\mu}(* 0.0001)$ & - & -1.2 & -1.2 & -1.1 & -0.31 & -1.6 \\
\hline$\sigma(* 0.0001)$ & - & 13.1 & 13.1 & 13 & 9.8 & 18 \\
\hline$\tilde{\sigma}(* 0.0001)$ & - & 15.35 & 15.3 & 15.15 & 12.5 & 20.9 \\
\hline$\beta$ & - & - & - & -0.06 & -0.06 & -0.03 \\
\hline$\mu^{V}(* 0.0001)$ & - & - & 0.9 & 0.04 & 0.01 & 0.2 \\
\hline$\tilde{\mu}^{V}(* 0.0001)$ & - & - & 1.8 & 0.06 & 0.02 & 0.4 \\
\hline $\begin{array}{l}\text { Annual price jump } \\
\text { risk premium }\end{array}$ & - & $13.7 \%$ & $13.7 \%$ & $11.4 \%$ & $5.9 \%$ & $17.8 \%$ \\
\hline
\end{tabular}

The price jump risk premium is $\lambda^{p} \bar{\mu}^{p}-\tilde{\lambda}^{p} \tilde{\bar{\mu}}$, with the drift compensator defined in Section 3.1.

Panel B Comparisons of estimated and selected parameters with previous studies

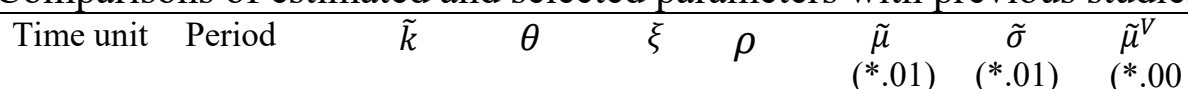

\begin{tabular}{llrlrrrrrrr}
\hline Pan & year & 7.1 & 0.013 & 0.28 & -0.52 & -0.3 & 3.25 & - & - & 27.1 \\
Wang & year & 1.6 & 0.044 & 0.367 & -0.64 & -13.3 & 2.19 & 680 & -0.47 & 0.25 \\
CGGT* $^{*}$ & year & 3.6 & 0.206 & 0.272 & -0.46 & -1.52 & 1.73 & 181 & -0.87 & 1.7
\end{tabular}

Our estimation and simulation:

\begin{tabular}{|c|c|c|c|c|c|c|c|c|c|c|c|}
\hline \multirow[t]{3}{*}{ Estimation } & year & Full & 7.0 & 0.004 & 0.45 & -0.60 & -0.37 & 1.77 & 319 & -0.11 & 0.38 \\
\hline & & Low & 7.0 & 0.004 & 0.45 & -0.65 & -0.24 & 2.63 & 1584 & -0.11 & 0.16 \\
\hline & & High & 6.8 & 0.010 & 0.46 & -0.52 & -0.37 & 1.66 & 83 & -0.08 & 1.28 \\
\hline \multirow[t]{3}{*}{ Simulation } & year & Full & 7.0 & 0.004 & 0.45 & -0.01 & -0.0110 & 0.152 & 0.06 & -0.06 & 2300 \\
\hline & & Low & 7.0 & 0.004 & 0.45 & -0.01 & -0.0031 & 0.125 & 0.20 & -0.06 & 2000 \\
\hline & & High & 6.8 & 0.010 & 0.46 & -0.01 & -0.0160 & 0.209 & 0.40 & -0.03 & 3000 \\
\hline \multirow[t]{2}{*}{ EJP* } & day & & 0.026 & 0.54 & 0.08 & -0.48 & -1.75 & 2.89 & 1.48 & -0.60 & 0.006 \\
\hline & & & & e-4 & e-2 & & & & & & \\
\hline \multirow[t]{2}{*}{ Eraker } & day & & 0.023 & 1.353 & 0.163 & -0.58 & -6.1 & 3.63 & 1.63 & -0.69 & 0.002 \\
\hline & & & & e-4 & e-2 & & & & & & \\
\hline
\end{tabular}

The parameters are estimated with annual time units by Pan (2002), CGGT (2003) and Wang (2009) and with daily time units by Eraker, Johannes, and Polson (EJP) (2003) and Eraker (2004). Our estimation parameters are obtained by matching the theoretical prices of Duffie, Pan, and Singleton (2000) with the 7-minute market prices. *: The parameters of CGGT (2003) and EJP (2003) are estimated from the real-world measure; the others are from the risk-neutral measure. 
TABLE 7 Detected jumps in futures and options prices when the SV, SVJP, and SVIJ models are simulated

\begin{tabular}{|c|c|c|c|c|c|c|c|c|c|c|c|c|c|c|c|}
\hline \multirow{2}{*}{$\begin{array}{r}\alpha \\
(\%)\end{array}$} & \multicolumn{3}{|c|}{$\begin{array}{c}\text { Detected jumps } \\
\text { per } 808 \text { days }\end{array}$} & \multicolumn{8}{|c|}{ Percentages of jump combinations } & \multirow[b]{2}{*}{$\begin{array}{l}\mathrm{CP} \\
+-\end{array}$} & \multirow[b]{2}{*}{$\begin{array}{l}\mathrm{CP} \\
-+\end{array}$} & \multirow[b]{2}{*}{$\begin{array}{l}\text { CP } \\
++\end{array}$} & \multirow[b]{2}{*}{$\begin{array}{l}\mathrm{CP} \\
--\end{array}$} \\
\hline & $\mathrm{F}$ & C & $\mathrm{P}$ & $\mathrm{C}$ & $\begin{array}{l}\mathrm{P} \\
+\end{array}$ & $\begin{array}{c}\mathrm{P} \\
-\end{array}$ & CP & $\mathrm{F}$ & $\mathrm{FC}$ & FP & FCP & & & & \\
\hline \multicolumn{16}{|c|}{ A. SV model result } \\
\hline 1 & 12.3 & 13.0 & 13.1 & 28 & 15 & 15 & 0 & 15 & 13 & 10 & 4 & 0.0 & 0.0 & 0.0 & 0.0 \\
\hline 0.1 & 1.6 & 1.8 & 1.7 & 30 & 16 & 15 & 0 & 17 & 11 & 9 & 2 & 0.0 & 0.0 & 0.0 & 0.0 \\
\hline 0.01 & 0.2 & 0.3 & 0.3 & 31 & 16 & 14 & 0 & 22 & 6 & 8 & 3 & 0.0 & 0.0 & 0.0 & 0.0 \\
\hline 0.001 & 0.04 & 0.02 & 0.05 & 17 & 17 & 22 & 0 & 35 & 0 & 4 & 4 & 0.0 & 0.0 & 0.0 & 0.0 \\
\hline \multicolumn{16}{|c|}{ B. Empirical result } \\
\hline 1 & 306 & 431 & 423 & 22 & 10 & 11 & 11 & 10 & 5 & 4 & 27 & 4.9 & 5.7 & 0.3 & 0.1 \\
\hline 0.1 & 150 & 217 & 228 & 22 & 12 & 12 & 11 & 6 & 6 & 6 & 26 & 4.7 & 5.3 & 0.3 & 0.3 \\
\hline 0.01 & 79 & 128 & 127 & 24 & 11 & 12 & 11 & 5 & 5 & 5 & 26 & 5.7 & 4.7 & 0.0 & 0.5 \\
\hline 0.001 & 45 & 65 & 90 & 18 & 17 & 16 & 12 & 5 & 3 & 9 & 20 & 8.2 & 4.1 & 0.0 & 0.0 \\
\hline \multicolumn{16}{|c|}{ C1. SVJP model result } \\
\hline 1 & 310 & 441 & 422 & 20 & 9 & 9 & 8 & 0.6 & 5 & 3 & 46 & 3.5 & 4.2 & 0.0 & 0.0 \\
\hline 0.1 & 165 & 257 & 241 & 22 & 10 & 9 & 9 & 0.4 & 4 & 3 & 42 & 4.0 & 5.0 & 0.0 & 0.0 \\
\hline 0.01 & 95 & 155 & 145 & 24 & 11 & 9 & 9 & 0.3 & 4 & 3 & 40 & 4.2 & 5.0 & 0.0 & 0.0 \\
\hline 0.001 & 58 & 98 & 92 & 24 & 11 & 10 & 10 & 0.3 & 3 & 3 & 39 & 5.2 & 4.9 & 0.0 & 0.0 \\
\hline \multicolumn{16}{|c|}{ C2. Constraint: only consider price jump risk premium: $\tilde{\mu} \neq \mu, \tilde{\sigma} \neq \sigma$} \\
\hline 1 & 316 & 444 & 425 & 20 & 9 & 9 & 6 & 0.5 & 5 & 3 & 47 & 2.8 & 3.6 & 0.0 & 0.0 \\
\hline 0.1 & 172 & 259 & 241 & 22 & 9 & 9 & 7 & 0.5 & 4 & 3 & 44 & 3.2 & 4.2 & 0.0 & 0.0 \\
\hline 0.01 & 100 & 154 & 147 & 23 & 10 & 9 & 8 & 0.4 & 4 & 3 & 42 & 3.7 & 4.6 & 0.0 & 0.0 \\
\hline 0.001 & 61 & 99 & 93 & 24 & 11 & 10 & 8 & 0.3 & 4 & 3 & 40 & 3.6 & 4.6 & 0.0 & 0.0 \\
\hline \multicolumn{16}{|c|}{ C3. Constraint: only consider intensity risk premium: $\tilde{\lambda}^{p} \neq \lambda^{p}$} \\
\hline 1 & 309 & 302 & 292 & 10 & 5 & 5 & 1.7 & 3.2 & 13 & 11 & 51 & 0.8 & 0.9 & 0.0 & 0.0 \\
\hline 0.1 & 165 & 163 & 155 & 12 & 5 & 5 & 1.8 & 3.7 & 13 & 11 & 48 & 0.8 & 0.9 & 0.0 & 0.0 \\
\hline 0.01 & 95 & 93 & 88 & 12 & 6 & 6 & 1.9 & 4.5 & 14 & 11 & 46 & 1.0 & 0.9 & 0.0 & 0.0 \\
\hline 0.001 & 57 & 56 & 53 & 13 & 6 & 5 & 2.0 & 4.7 & 13 & 11 & 44 & 1.0 & 0.9 & 0.0 & 0.0 \\
\hline \multicolumn{16}{|c|}{ C4. Constraint: no jump risk premium and no intensity risk premium } \\
\hline 1 & 314 & 302 & 289 & 11 & 5 & 5 & 0.3 & 3.3 & 13 & 11 & 52 & 0.1 & 0.2 & 0.0 & 0.0 \\
\hline 0.1 & 168 & 160 & 156 & 11 & 6 & 5 & 0.4 & 3.6 & 13 & 11 & 49 & 0.2 & 0.2 & 0.0 & 0.0 \\
\hline 0.01 & 96 & 91 & 90 & 11 & 6 & 6 & 0.5 & 3.7 & 13 & 11 & 49 & 0.2 & 0.3 & 0.0 & 0.0 \\
\hline 0.001 & 59 & 56 & 54 & 12 & 5 & 5 & 0.5 & 4.1 & 13 & 11 & 48 & 0.2 & 0.3 & 0.0 & 0.0 \\
\hline \multicolumn{16}{|c|}{ C5. Estimated parameters from $\operatorname{Pan}(2002)$} \\
\hline 1 & 91 & 92 & 89 & 5 & 1.9 & 1.9 & 0 & 1.4 & 4 & 2 & 83 & 0.0 & 0.0 & 0.0 & 0.0 \\
\hline 0.1 & 81 & 82 & 79 & 2 & 0.3 & 0.3 & 0 & 0.4 & 2 & 0 & 95 & 0.0 & 0.0 & 0.0 & 0.0 \\
\hline 0.01 & 79 & 79 & 77 & 1 & 0.1 & 0.1 & 0 & 0.1 & 2 & 0 & 97 & 0.0 & 0.0 & 0.0 & 0.0 \\
\hline 0.001 & 78 & 78 & 76 & 1 & 0.1 & 0.0 & 0 & 0.0 & 2 & 0 & 97 & 0.0 & 0.0 & 0.0 & 0.0 \\
\hline \multicolumn{16}{|c|}{ D. SVIJ model result } \\
\hline 1 & 302 & 443 & 431 & 18 & 8 & 8 & 11 & 0.2 & 2 & 2 & 51 & 5.0 & 5.7 & 0.0 & 0.0 \\
\hline 0.1 & 162 & 255 & 247 & 19 & 9 & 9 & 12 & 0.1 & 2 & 1 & 48 & 5.6 & 6.4 & 0.0 & 0.0 \\
\hline 0.01 & 91 & 153 & 146 & 22 & 10 & 9 & 13 & 0.1 & 2 & 1 & 44 & 5.5 & 7.2 & 0.0 & 0.0 \\
\hline 0.001 & 54 & 94 & 92 & 22 & 11 & 10 & 13 & 0.0 & 2 & 1 & 42 & 5.3 & 7.6 & 0.0 & 0.0 \\
\hline
\end{tabular}


TABLE 8 Detected jumps in futures and options prices when the SVCJ model is simulated

\begin{tabular}{|c|c|c|c|c|c|c|c|c|c|c|c|c|c|c|c|}
\hline \multirow{2}{*}{${ }_{(\%)}^{\alpha}$} & \multicolumn{3}{|c|}{$\begin{array}{c}\text { Detected jumps } \\
\text { per } 808 \text { days }\end{array}$} & \multicolumn{8}{|c|}{ Percentages of jump combinations } & \multirow[b]{2}{*}{$\begin{array}{l}\mathrm{CP} \\
+-\end{array}$} & \multirow[b]{2}{*}{$\begin{array}{l}\text { CP } \\
-+\end{array}$} & \multirow[b]{2}{*}{$\begin{array}{l}\text { CP } \\
++\end{array}$} & \multirow[b]{2}{*}{$\begin{array}{l}\mathrm{CP} \\
--\end{array}$} \\
\hline & $\mathrm{F}$ & $\mathrm{C}$ & $\mathrm{P}$ & $\mathrm{C}$ & $\begin{array}{l}\mathrm{P} \\
+\end{array}$ & $\begin{array}{c}P \\
-\end{array}$ & $\mathrm{CP}$ & $\mathrm{F}$ & $\mathrm{FC}$ & FP & FCP & & & & \\
\hline \multicolumn{16}{|c|}{ A1. Empirical result, full sample period } \\
\hline 1 & 306 & 431 & 423 & 22 & 10 & 11 & 11 & 10 & 5 & 4 & 27 & 4.9 & 5.7 & 0.3 & 0.1 \\
\hline 0.1 & 150 & 217 & 228 & 22 & 12 & 12 & 11 & 6 & 6 & 6 & 26 & 4.7 & 5.3 & 0.3 & 0.3 \\
\hline 0.01 & 79 & 128 & 127 & 24 & 11 & 12 & 11 & 5 & 5 & 5 & 26 & 5.7 & 4.7 & 0.0 & 0.5 \\
\hline 0.001 & 45 & 65 & 90 & 18 & 17 & 16 & 12 & 5 & 3 & 9 & 20 & 8.2 & 4.1 & 0.0 & 0.0 \\
\hline \multicolumn{16}{|c|}{ B1. SVCJ model result } \\
\hline 1 & 304 & 438 & 422 & 19 & 9 & 8 & 8 & 0.4 & 4 & 3 & 48 & 3.9 & 4.5 & 0.0 & 0.0 \\
\hline 0.1 & 165 & 255 & 244 & 21 & 9 & 9 & 10 & 0.2 & 3 & 3 & 44 & 4.4 & 5.4 & 0.0 & 0.0 \\
\hline 0.01 & 93 & 155 & 145 & 23 & 10 & 9 & 11 & 0.1 & 3 & 2 & 41 & 4.6 & 6.2 & 0.0 & 0.0 \\
\hline 0.001 & 55 & 98 & 91 & 24 & 11 & 9 & 12 & 0.2 & 3 & 2 & 38 & 5.3 & 6.7 & 0.0 & 0.0 \\
\hline
\end{tabular}

B2. Constraint: only consider price jump risk premium: $\tilde{\mu} \neq \mu, \tilde{\sigma} \neq \sigma$

\begin{tabular}{rrrr|rrrrrrrr|rrrr}
1 & 306 & 432 & 418 & 19 & 9 & 8 & 7 & 0.4 & 4 & 3 & 49 & 3.2 & 3.9 & 0.0 & 0.0 \\
0.1 & 164 & 250 & 239 & 21 & 10 & 9 & 9 & 0.2 & 3 & 3 & 45 & 4.1 & 4.6 & 0.0 & 0.0 \\
0.01 & 94 & 151 & 145 & 22 & 10 & 9 & 9 & 0.1 & 3 & 2 & 43 & 4.4 & 4.9 & 0.0 & 0.0 \\
0.001 & 58 & 96 & 92 & 23 & 11 & 10 & 10 & 0.1 & 3 & 2 & 41 & 5.0 & 5.0 & 0.0 & 0.0
\end{tabular}

B3. Constraint: only consider volatility jump risk premium: $\tilde{\mu}^{V} \neq \mu^{V}$

\begin{tabular}{rrrr|rrrrrrrr|rrrr}
1 & 306 & 276 & 266 & 10 & 5 & 5 & 0.2 & 5 & 15 & 13 & 47 & 0.1 & 0.1 & 0.0 & 0.0 \\
0.1 & 164 & 147 & 141 & 10 & 5 & 5 & 0.3 & 6 & 15 & 13 & 46 & 0.2 & 0.1 & 0.0 & 0.0 \\
0.01 & 94 & 84 & 80 & 10 & 5 & 5 & 0.3 & 7 & 16 & 12 & 44 & 0.2 & 0.1 & 0.0 & 0.0 \\
0.001 & 57 & 52 & 47 & 12 & 4 & 5 & 0.3 & 8 & 16 & 12 & 44 & 0.3 & 0.1 & 0.0 & 0.0
\end{tabular}

B4. Constraint: only consider intensity risk premium: $\tilde{\lambda}^{p} \neq \lambda^{p}$

\begin{tabular}{rrrr|rrrrrrrr|rrrr}
1 & 303 & 279 & 267 & 10 & 4 & 5 & 1.4 & 5.4 & 15 & 13 & 46 & 0.6 & 0.9 & 0.0 & 0.0 \\
0.1 & 162 & 151 & 139 & 11 & 5 & 5 & 1.7 & 6.5 & 16 & 12 & 44 & 0.7 & 0.9 & 0.0 & 0.0 \\
0.01 & 92 & 85 & 79 & 12 & 5 & 5 & 1.5 & 6.5 & 15 & 13 & 42 & 0.7 & 0.8 & 0.0 & 0.0 \\
0.001 & 57 & 51 & 49 & 12 & 5 & 5 & 1.4 & 6.3 & 15 & 14 & 41 & 0.7 & 0.7 & 0.0 & 0.0
\end{tabular}

B5. Constraint: no jump risk premium, volatility jump risk premium, and intensity risk premium

\begin{tabular}{rrrr|rrrrrrrr|rrrr}
1 & 308 & 280 & 267 & 10 & 4 & 5 & 0.2 & 5.1 & 15 & 12 & 48 & 0.1 & 0.1 & 0.0 & 0.0 \\
0.1 & 167 & 150 & 142 & 10 & 5 & 5 & 0.3 & 5.7 & 16 & 13 & 45 & 0.1 & 0.2 & 0.0 & 0.0 \\
0.01 & 97 & 83 & 80 & 11 & 4 & 5 & 0.4 & 7.5 & 16 & 14 & 43 & 0.2 & 0.2 & 0.0 & 0.0 \\
0.001 & 57 & 51 & 49 & 12 & 6 & 4 & 0.3 & 7.4 & 15 & 12 & 43 & 0.1 & 0.2 & 0.0 & 0.0
\end{tabular}

B6. Estimated parameters from CGGT (2003)

\begin{tabular}{rrrr|rrrrrrrr|rrrr}
1 & 17 & 19 & 18 & 17 & 8 & 9 & 0.3 & 1.6 & 12 & 7 & 45 & 0.2 & 0.0 & 0.1 & 0.0 \\
0.1 & 7 & 8 & 7 & 10 & 5 & 4 & 0.6 & 0.3 & 6 & 6 & 69 & 0.0 & 0.3 & 0.3 & 0.0 \\
0.01 & 6 & 6 & 6 & 2 & 2 & 1 & 0.4 & 0.4 & 2 & 4 & 88 & 0.0 & 0.0 & 0.4 & 0.0 \\
0.001 & 5 & 5 & 6 & 1 & 3 & 0 & 0.5 & 0.0 & 0 & 3 & 92 & 0.0 & 0.0 & 0.5 & 0.0
\end{tabular}

B7. Our estimated parameters from Panel B of Table 6

\begin{tabular}{|c|c|c|c|c|c|c|c|c|c|c|c|c|c|c|c|}
\hline \\
\hline 1 & 13 & 14 & 15 & 26 & 14 & 16 & 1 & 13 & 13 & 11 & 7 & 0.0 & 0.1 & 0.6 & 0.0 \\
\hline 0.1 & 2 & 3 & 3 & 23 & 14 & 13 & 4 & 13 & 9 & 9 & 15 & 0.0 & 0.0 & 3.6 & 0.0 \\
\hline 0.01 & 1 & 1 & 1 & 14 & 8 & 3 & 11 & 7 & 8 & 10 & 38 & 0.0 & 0.0 & 11.2 & 0.0 \\
\hline 0.001 & 1 & 1 & 1 & 4 & 4 & 0 & 18 & 2 & 7 & 14 & 51 & 0.0 & 0.0 & 18.2 & 0.0 \\
\hline \multicolumn{16}{|c|}{ C1. Empirical result, low volatility period } \\
\hline 1 & 324 & 528 & 519 & 27 & 13 & 14 & 8 & 6 & 7 & 6 & 19 & 3.6 & 4.1 & 0.3 & 0.3 \\
\hline 0.1 & 149 & 252 & 250 & 31 & 14 & 15 & 6 & 7 & 5 & 6 & 17 & 2.5 & 3.0 & 0.0 & 0.0 \\
\hline 0.01 & 61 & 136 & 145 & 33 & 17 & 15 & 9 & 3 & 3 & 8 & 12 & 4.6 & 4.6 & 0.0 & 0.0 \\
\hline 0.001 & 39 & 74 & 94 & 31 & 22 & 15 & 6 & 4 & 1 & 9 & 12 & 4.4 & 1.5 & 0.0 & 0.0 \\
\hline \multicolumn{16}{|c|}{ C2. SVCJ model result } \\
\hline 1 & 333 & 535 & 505 & 22 & 9 & 9 & 11 & 0.7 & 4 & 2 & 42 & 5.2 & 5.6 & 0.0 & 0.0 \\
\hline 0.1 & 185 & 331 & 306 & 24 & 9 & 10 & 12 & 0.3 & 3 & 2 & 38 & 5.9 & 6.4 & 0.0 & 0.0 \\
\hline 0.01 & 109 & 213 & 192 & 27 & 10 & 10 & 13 & 0.2 & 3 & 2 & 35 & 6.8 & 6.5 & 0.0 & 0.0 \\
\hline
\end{tabular}




\begin{tabular}{|c|c|c|c|c|c|c|c|c|c|c|c|c|c|c|c|}
\hline 0.001 & 67 & 140 & 126 & 28 & 11 & 11 & 14 & 0.2 & 3 & 2 & 33 & 6.8 & 7.2 & 0.0 & 0.0 \\
\hline \multicolumn{16}{|c|}{ D1. Empirical result, high volatility period } \\
\hline 1 & 252 & 364 & 396 & 15 & 10 & 9 & 20 & 9 & 2 & 5 & 31 & 8.2 & 11.3 & 0.0 & 0.0 \\
\hline 0.1 & 123 & 180 & 204 & 15 & 11 & 12 & 17 & 9 & 2 & 3 & 30 & 6.6 & 10.6 & 0.0 & 0.0 \\
\hline 0.01 & 59 & 92 & 107 & 20 & 19 & 8 & 13 & 8 & 1 & 4 & 25 & 6.0 & 7.2 & 0.0 & 0.0 \\
\hline 0.001 & 29 & 39 & 70 & 17 & 17 & 20 & 11 & 0 & 0 & 17 & 17 & 2.2 & 8.7 & 0.0 & 0.0 \\
\hline \multicolumn{16}{|c|}{ D2. SVCJ model result } \\
\hline 1 & 246 & 382 & 379 & 18 & 9 & 8 & 12 & 0.1 & 2 & 2 & 48 & 5.5 & 6.8 & 0.0 & 0.0 \\
\hline 0.1 & 123 & 206 & 207 & 19 & 10 & 9 & 15 & 0.1 & 1 & 1 & 44 & 6.6 & 8.2 & 0.0 & 0.0 \\
\hline 0.01 & 68 & 120 & 120 & 20 & 11 & 9 & 15 & 0.0 & 1 & 1 & 42 & 6.6 & 8.4 & 0.0 & 0.0 \\
\hline 0.001 & 41 & 75 & 73 & 21 & 11 & 8 & 16 & 0.0 & 2 & 1 & 41 & 7.7 & 8.3 & 0.0 & 0.0 \\
\hline
\end{tabular}


1 The only other study known to us which tests for option price jumps using intraday option prices is the concurrent work of Kapetanios, Neumann, and Skiadopoulos (2014). They investigate S\&P 500 Emini futures options from 2005 to 2010.

${ }^{2}$ Yun (2014) investigates a time-varying jump intensity premium, with $\lambda^{p}$ a constant and $\tilde{\lambda}^{p}$ proportional to $V$.

3 The OTM calls (puts) have moneyness, K/S , approximately equal on average to $1.01(0.99)$.

4 A serious violation of put-call parity is defined as an unusual spike in the prices of calls or puts, larger than one-third of the daily call or put price range.

${ }^{5}$ For comparison, signature plots for the S\&P 500 index are provided by Kapetanios, Neumann, and Skiadopoulos (2014) and Audrino and Fengler (2015).

6 The mean realized variance is the average across days $d$ of the realized variance defined by (2).

${ }^{7}$ Our selected price jump risk premia (defined in Table 6) are similar to those of Pan (2002), in whose study the price jump risk premia ranged from approximately $13 \%$ to $21 \%$. Broadie, Chernov, and Johannes (2007) used the S\&P 500 futures options from 1987 to 2003. They estimated the SVJ mean price jump risk premium to be in the approximate range of $3 \%$ to $6 \%$, and the SVCJ mean price jump risk premium to range from $2 \%$ to $4 \%$.

${ }^{8}$ Note there is no microstructure noise in the simulated prices, while there will be some noise in the FTSE prices due to bid/ask spreads etc. 